\title{
The miR-96 and RARy signaling axis governs androgen signaling and prostate cancer progression
}

\author{
Mark D. Long ${ }^{1}$ - Prashant K. Singh ${ }^{2}$ - James R. Russell ${ }^{1}$ Gerard Llimos ${ }^{1,3}$. Spencer Rosario ${ }^{1}$ Abbas Rizvi ${ }^{4}$. \\ Patrick R. van den Berg ${ }^{1,5}$. Jason Kirk ${ }^{6}$. Lara E. Sucheston-Campbell ${ }^{4,7}$ • Dominic J. Smiraglia $\mathbb{B}^{1}$. \\ Moray J. Campbell
}

Received: 21 December 2017 / Revised: 25 April 2018 / Accepted: 26 June 2018 / Published online: 17 August 2018

(c) The Author(s) 2018. This article is published with open access

\begin{abstract}
Expression levels of retinoic acid receptor gamma (NRIB3/RARG, encodes RAR $\gamma$ ) are commonly reduced in prostate cancer (PCa). Therefore, we sought to establish the cellular and gene regulatory consequences of reduced RAR $\gamma$ expression, and determine RAR $\gamma$ regulatory mechanisms. RARG shRNA approaches in non-malignant (RWPE-1 and HPr1-AR) and malignant (LNCaP) prostate models revealed that reducing RAR $\gamma$ levels, rather than adding exogenous retinoid ligand, had the greatest impact on prostate cell viability and gene expression. ChIP-Seq defined the RAR $\gamma$ cistrome, which was significantly enriched at active enhancers associated with AR binding sites. Reflecting a significant genomic role for RAR $\gamma$ to regulate androgen signaling, RAR $\gamma$ knockdown in HPrl-AR cells significantly regulated the magnitude of the AR transcriptome. RAR $\gamma$ downregulation was explained by increased miR-96 in PCa cell and mouse models, and TCGA PCa cohorts. Biochemical approaches confirmed that miR-96 directly regulated RAR $\gamma$ expression and function. Capture of the miR-96 targetome by biotin-miR-96 identified that RAR $\gamma$ and a number of RAR $\gamma$ interacting co-factors including TACC1 were all targeted by miR-96, and expression of these genes were prominently altered, positively and negatively, in the TCGA-PRAD cohort. Differential gene expression analyses between tumors in the TCGA-PRAD cohort with lower quartile expression levels of $R A R G$ and $T A C C 1$ and upper quartile miR-96, compared to the reverse, identified a gene network including several RAR $\gamma$ target genes (e.g., SOX15) that significantly associated with worse disease-free survival (hazard ratio $2.23,95 \%$ CI 1.58 to $2.88, p=0.015$ ). In summary, miR-96 targets a RAR $\gamma$ network to govern AR signaling, PCa progression and disease outcome.
\end{abstract}

Electronic supplementary material The online version of this article (https://doi.org/10.1038/s41388-018-0450-6) contains supplementary material, which is available to authorized users.

Moray J. Campbell

campbell.1933@osu.edu

1 Department of Cancer Genetics and Genomics, Roswell Park Comprehensive Cancer Center (RPCCC), Buffalo, NY 14263, USA

2 Center for Personalized Medicine, Roswell Park Comprehensive Cancer Center, Buffalo, NY 14263, USA

3 Institute of Bioengineering, École Polytechnique Fédérale de Lausanne (EPFL), Lausanne, Switzerland

4 College of Pharmacy, The Ohio State University, Columbus, $\mathrm{OH}$

\section{Introduction}

Members of the nuclear hormone receptor (NR) superfamily are ubiquitously expressed across tissues and govern cell fate decisions. One NR, the androgen receptor (NR3C4/AR), is a key regulator of growth and differentiation in the prostate gland [1]. Genomic approaches in prostate cancer

\section{0, USA}

5 Leiden institute of Physics, Leiden University, 2300 RA Leiden, The Netherlands

6 Department of Pharmacology \& Therapeutics, Roswell Park Comprehensive Cancer Center, Buffalo, NY 14263, USA

7 College of Veterinary Medicine, The Ohio State University, Columbus, OH 43210, USA

8 Division of Pharmaceutics and Pharmaceutical Chemistry, College of Pharmacy, The Ohio State University, 536 Parks Hall, Columbus, OH 43210, USA 

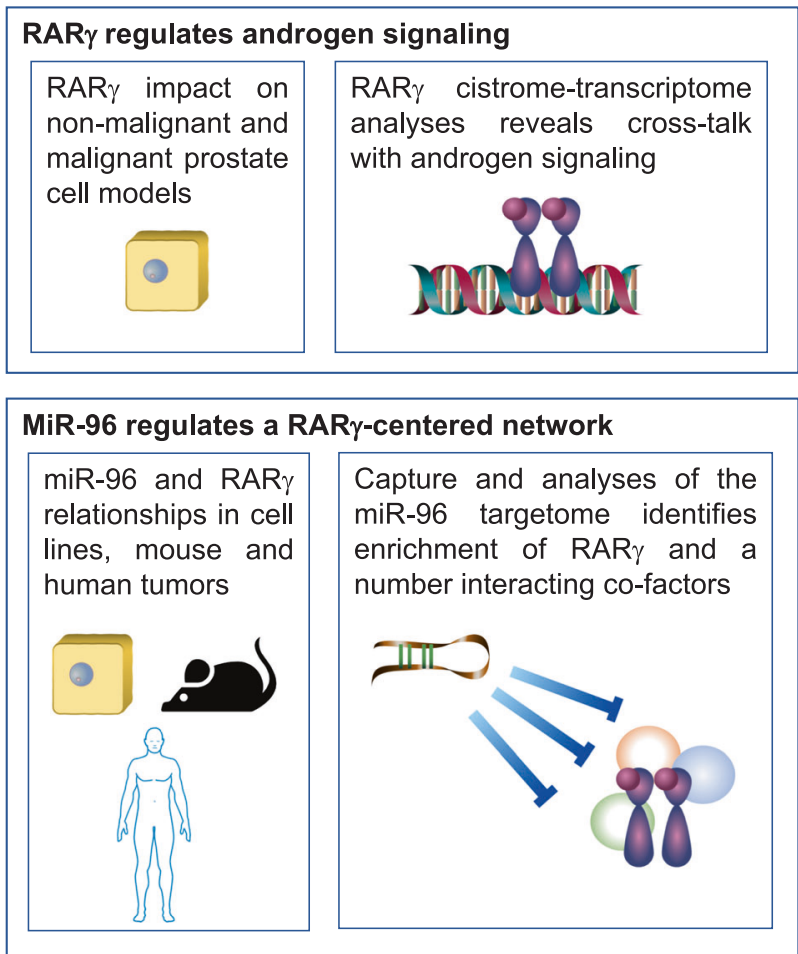

miR-96/RAR $\gamma$ combine to predict the hazard of prostate cancer progression

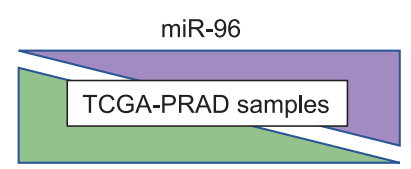

RAR $\gamma$ \& TACC 1

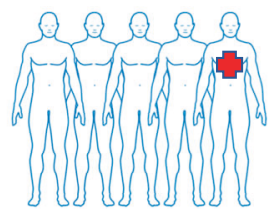

Fig. 1 The workflow for investigating the consequences of altered RAR $\gamma$ expression in cell line, murine and human prostate cells, and how miR-96 regulates $\mathrm{RAR} \gamma$ to drive aggressive prostate cancer

(PCa) have identified that the signaling capacity of the androgen receptor (AR) becomes skewed with disease progression [2]. A normal component of AR signaling is to drive terminal differentiation of luminal epithelial cells and this function is disrupted in PCa [3]. The disruption, or rewiring, of AR actions changes both the receptor sensitivity, defined as the magnitude of the transcriptional response, and capacity, defined as the selection of gene networks governed. Although the AR is a pharmacological target in later PCa stages, its disruption at early-stage disease is more nuanced.

In fact, multiple NRs are expressed in the normal prostate and are disrupted in PCa. NR actions are integrated by shared genomic binding regions, shared co-factors and the co-regulation of ligand availability [4]. Noncoding RNAs including microRNA (miRNA) and long noncoding RNA target NRs, their co-factors and target genes to exert further control of signaling [5, 6]. Ultimately, these different aspects of NR regulation combine to modulate transcriptional sensitivity.

Previously, as a route to identify how NR networks are disrupted in cancer, we undertook an analysis of the NR superfamily across cancers in The Cancer Genome Atlas (TCGA). Our analyses revealed significantly distinct NR profiles within different tumor types [7]. Specifically, in the Taylor et al. [8] Memorial Sloan-Kettering Cancer Center (MSKCC) and TCGA Prostate Adenocarcinoma (TCGAPRAD) PCa cohorts [9], the retinoic acid receptor gamma (NR1B3/RARG, encodes RAR $\gamma$ ) and glucocorticoid receptor $(N R 3 C 1 / G R)$ were significantly and uniquely downregulated compared to other cancers. By contrast, expression of the $A R$ was not significantly altered in either cohort. There was only one $R A R G$ mutation and relatively few copy number variations detected at the $R A R G$ locus across these approximately $600 \mathrm{PCa}$ samples.

There are three human RAR paralogs, namely RAR $\alpha$, RAR $\beta$ and RAR $\gamma$. In PCa, RAR $\beta$ appears to act as a tumor suppressor silenced by DNA methylation [10, 11]. Curiously, while there are observed roles for RAR $\gamma$ in prostatic development [12], its role and regulatory functions in prostate cells and $\mathrm{PCa}$ remain enigmatic, as do its upstream control mechanisms. Furthermore, pharmacologic targeting of these receptors has been investigated, for example, with pan- and paralog-specific retinoid ligands with the goal to induce differentiation [13]. However the extent to which RAR functions are directly associated either with ligand activating events or indirectly through interactions with other transcription factors, is similarly underexplored.

To better understand the consequences and causes of reduced $\operatorname{RAR} \gamma$ expression levels in prostate cells we designed a workflow combining analyses in prostate cell lines, murine models and human tumors (Fig. 1). Specifically, in each of two non-malignant models (RWPE-1 and HPr1-AR) and in one malignant model (LNCaP) we generated two independent clones with stable RAR $\gamma$ knockdown. In these control and knockdown clones we examined the effects on cell viability and gene expression from either changing the baseline RAR $\gamma$ expression levels or adding exogenous ligand. These data revealed that reducing RAR $\gamma$ expression levels had a bigger impact on cell viability and gene expression than adding exogenous ligand. Notable in the enriched terms of the RAR $\gamma$-regulated gene networks were terms related to nuclear factor (NF)- $\mathrm{\kappa B}$, hypoxia and androgen signaling. In RWPE-1 cells, we undertook RAR $\gamma$ chromatin immunoprecipitation-sequencing (ChIP-Seq) to identify the RAR $\gamma$ cistrome. Without adding exogenous ligand, $\operatorname{RAR} \gamma$ significantly associated with active gene enhancers and also significantly overlapped with the binding sites for other transcription factor functions, including $\mathrm{AR}$ and also the NF- $\mathrm{kB}$ component RELA/p65. Testing if 
RAR $\gamma$ regulated AR was undertaken by androgendependent transcriptomic analyses in HPr1-AR cells with stable knockdown of RAR $\gamma$ expression. This revealed that RAR $\gamma$ expression levels potently regulated the capacity and sensitivity of AR. MiR-96 was identified as a major regulator of RAR $\gamma$ expression, which is commonly elevated in PCa and associated with disease progression. MiR-96 directly bound and regulated expression of $\operatorname{RAR} \gamma$, and capturing the miR-96 targetome revealed that this miRNA also targeted a number of known RAR $\gamma$ co-factors including TACC1 (transforming, acidic coiled-coil containing protein 1). Finally, tumors in the lower quartile $R A R G$ and TACC1 and upper quartile miR-96 were significantly associated with aggressive PCa and disease recurrence. Together, these findings suggest that RAR $\gamma$ expression levels potently regulate gene networks that are significantly intertwined with the regulation of AR sensitivity and capacity. Control of these actions is regulated by miR-96 and loss of this capacity predicts prostate cancer progression.

\section{Results}

\section{Reduced RARY expression in non-malignant and malignant prostate cell models increases cell viability and changes gene expression}

To test the cellular impact of reduced RAR $\gamma$ expression levels we generated clones with stable knocked-down of $\mathrm{RAR} \gamma$ in non-malignant prostate epithelial cells (RWPE-1) and LNCaP PCa cells using two separate RAR $\gamma$ targeting short hairpin RNA (shRNA) constructs (Fig. 2a-d). The expression of the $\operatorname{RAR} \gamma$, paralogs $\operatorname{RAR} \alpha$ and $\operatorname{RAR} \beta$ were unaltered by the knockdown of RAR $\gamma$ (Fig. 2a, c).

In RWPE-1 and LNCaP cells in standard cell tissue culture conditions and without exogenous retinoids, RAR $\gamma$ knockdown in two separate clones significantly increased viability within $96 \mathrm{~h}$ (Fig. 3a). By contrast, stable RAR $\gamma$ knockdown only slightly reduced anti-proliferative sensitivity to either all-trans retinoic acid (ATRA) or a RAR $\gamma$ selective ligand (CD437) in RWPE-1 cells and not at all in LNCaP cells (Supplementary Figure 1A-D). Also, independent of exposure to ligand, RAR $\gamma$ knockdown significantly reduced the $\mathrm{G}_{2} / \mathrm{M}$ population in both RWPE-1 and LNCaP cells, whereas reduced RAR $\gamma$ levels changed CD437-induced $\mathrm{G}_{2} / \mathrm{M}$ blockade only in RWPE-1 cells (Supplementary Figure 1E, F). Together, these findings suggest that reducing RAR $\gamma$ expression has a significant impact on cell viability and cell cycle status, which is largely independent of the addition of exogenous retinoid ligand.

Stably reducing RAR $\gamma$ expression levels also exerted a significant impact on gene expression, compared to non- targeting vector controls. Meanwhile, the RAR $\gamma$-dependent CD437-induced response, defined as genes differentially regulated by CD437 in control shRNA (shCTL) cells but not (or to a significantly lesser extent) in shRARG cells, was more modest (RWPE-1) or negligible (LNCaP) (Fig. 3b, c, Supplementary Figure 2A-D). For instance, in RWPE-1 cells, 605 differentially expressed genes (DEGs) (1.2 fold change, Benjamini-Hochberg adjusted $p$ value ( $p$.adj) $<$ $0.05)$ were associated with the knockdown of RAR $\gamma$ regulation, whereas only 237 genes were responsive to CD437 $(10 \mathrm{nM}, 24 \mathrm{~h})$ in a RAR $\gamma$-dependent manner.

To infer gene functionality resulting from changes in RAR $\gamma$ expression, Gene Set Enrichment Analysis (GSEA) was applied to the RAR $\gamma$-dependent transcriptomes. In RWPE-1 cells, 435 pathways were enriched (normalized enrichment score (NES) $>1.8$, false discovery rate (FDR) $q$ val $<0.05$ ) in at least one comparison (Supplementary Figure 2E). Among these, 196 were associated uniquely with stable knockdown of RAR $\gamma$ and 201 with the addition of CD437, while 38 were common between categories.

Frequency mining of common GSEA pathway terms combined with hypergeometric testing established largely distinct enrichment of meta-groups (e.g., terms associated with NF-kB) between stable RAR $\gamma$ knockdown or CD437treated conditions (Fig. 3d). In RWPE-1 cells, the RAR $\gamma$ stable knockdown transcriptome was significantly enriched for terms associated with NF-KB and histone deacetylase function (Fig. 3e), whereas the CD437-treated transcriptome was enriched for terms related to Tretinoin (the commercial name for ATRA) (Fig. 3f), as well as for estrogen receptor- $\alpha(E R \alpha)$ function. In $\mathrm{LNCaP}$ cells the stable knockdown of RAR $\gamma$ gene regulatory effects were most pronounced (Supplementary Figure 2C, D) and highly enriched for hypoxia and AR responses (Fig. 3g, Supplementary Figure 2F).

We further explored the enrichment of AR terms in the transcriptome of stable knockdown of RAR $\gamma$ in LNCaP. Specifically, we used a previously compiled AR target gene panel [9] to demonstrate that expression of these genes alone significantly distinguished LNCaP-shRARG cells from controls in a CD437-independent manner (Fig. 3h). That is, applying unsupervised hierarchical clustering to expression patterns of these genes distinguished the LNCaP-shRARG from CD437-treated clones. Furthermore, the expression of KLK3 and TMPRSS2 was altered upon knockdown of RAR $\gamma$ in LNCaP cells and its loss altered by dihydroxytestosterone (DHT) regulation of these genes (Supplementary Figure 2G).

In total, stable knockdown of RAR $\gamma$ revealed that the functions of this receptor are substantial and intertwined with other transcription factors, notably the AR and NF- $\kappa B$, and these actions appear to be largely independent of the impact of treating cells with retinoid ligand. 

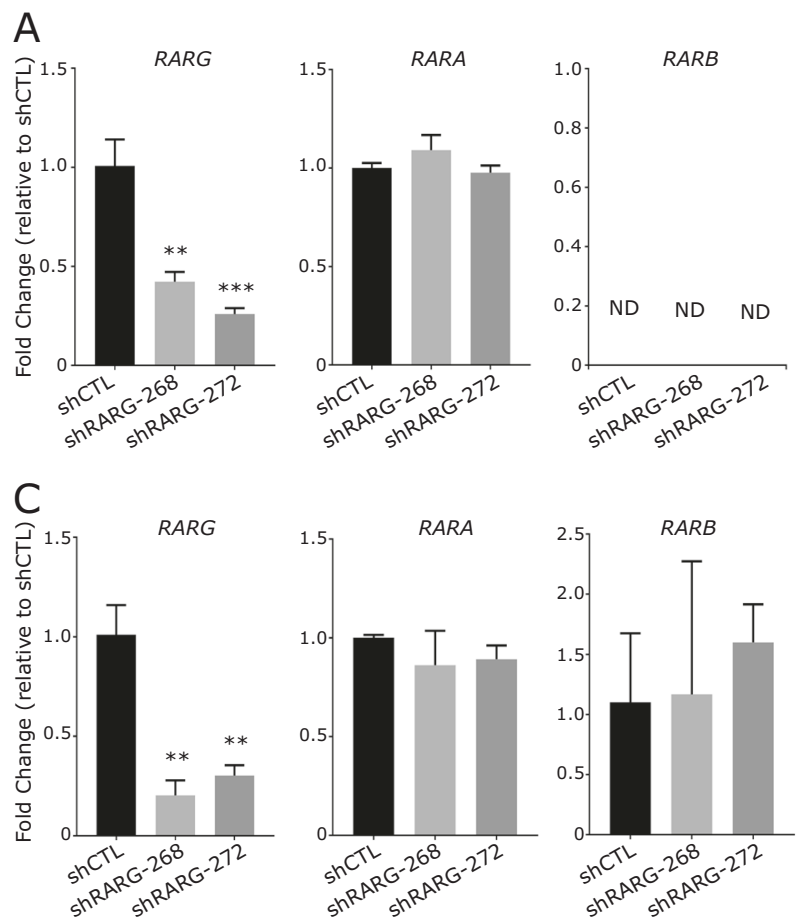

Fig. 2 Stable knockdown of RAR $\gamma$ in prostate cell lines. RWPE-1 (a, b) and $\mathrm{LNCaP}$ (c, d) cells were each stably transfected with two shRNA constructs targeting $R A R G$. a Validation of $R A R G$ knockdown, and unaltered expression of RARA and $R A R B$ mRNA and $\mathbf{b}$ RAR $\gamma$

\section{The RARY cistrome significantly overlaps with active enhancers, AR binding and associates with aggressive PCa}

Having established that changing RAR $\gamma$ expression levels can have a significant impact on gene expression, even in the absence of exogenous ligand, we next wished to measure the genomic distribution of RAR $\gamma$ in the presence and absence of exogenous retinoid ligand. To avoid the Type I error rate due to $\mathrm{RAR} \gamma$ paralog noise we used a green fluorescent protein (GFP)-tagged RAR $\gamma$ contained in a BAC (bacterial artificial chromosome) clone (kind gift of Dr. Kevin White (University of Chicago)). Indeed, these investigators demonstrated that commercially available RAR $\gamma$ antibodies were not able to yield high-quality chromatin for ChIP studies $[14,15]$. Although GFP-RAR $\gamma$ was modestly elevated compared to endogenous $\operatorname{RAR} \gamma$, this does not appear to be supra-physiological, like that which may occur with cytomegalovirus (CMV) and other strong regulatory promoters. Therefore, RAR $\gamma$-EGFP was stably transfected in RWPE-1 cells [14]; optimization studies revealed significant enrichment at previously established RAR $\gamma$-dependent genes including SMAD3 [16, 17] and FOXA1 [18] (Supplementary Figure 4A-C).

In the absence of exogenous retinoid, reflecting the transcriptomic data, the RAR $\gamma$ cistrome was considerably
B
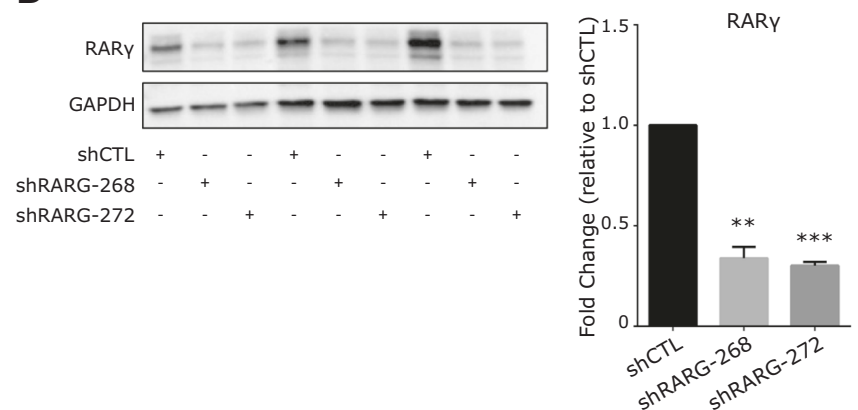

$\mathrm{D}$
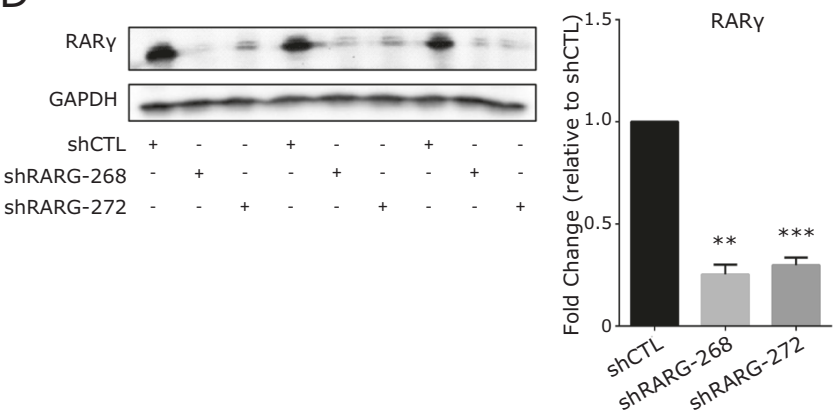

protein levels in RWPE-1-shCTL and RWPE-1-shRARG cells. $\mathbf{c}$, d Similar validation results are shown for LNCaP-shCTL and LNCaPshRARG cells. Significance of difference between shRARG and shCTL cells are noted $(* * p<0.01, * * * p<0.001)$

larger $(1256$ peaks $(p$.adj $<0.1)$ ) than the CD437-dependent cistrome of 360 peaks, of which 316 were shared and 44 were unique. Motif analyses of RAR $\gamma$ cistrome in the absence of exogenous retinoid revealed significant enrichment of transcription factor (TF) motifs for members of the AP1 family (FOSB/JUN; $E$ value $1.2 \mathrm{e}^{-80}$ ), the homeobox family (OTX2, PITX1; $E$ value $9.2 \mathrm{e}^{-12}$ ) and NRs (RXRs, RARs; $E$ value $\left.2.4 \mathrm{e}^{-9}\right)$. By contrast, after the addition of CD437 (10 nM, 2h) the RAR $\gamma$ cistrome was enriched uniquely for other homeobox family members (ONEC2, HXC10; $E$ value $\left.1.5 \mathrm{e}^{-14}\right)$ and PAX5 $\left(E\right.$ value $\left.6.1 \mathrm{e}^{-7}\right)$.

We characterized the RAR $\gamma$ cistrome further by examining its overlaps with publicly available ChIP-Seq data sets. We focused on two sources: firstly, ChIP-Seq and other genomic data sets derived in normal prostate cells and tissue and, secondly, those from across PCa models for the $\mathrm{AR}$ and other nuclear receptors, as well as NF- $\mathrm{KB}$ and other PCa-relevant factors including the ETS TF, ERG. Therefore, we examined the RAR $\gamma$ cistrome genomic distribution and overlap, within $100 \mathrm{bp}$, with ChIP-Seq data available in RWPE-1 cells, namely DNAse sensitivity, histone modifications (H3K27ac, H3K27me3, H3K4me1, H3K4me3) (GSE63094, GSM1541008), and the chromatin states track derived with ChromHMM [19] (personal communication, Dr. Mathieu Lupien (University of Toronto)). Alongside these, we examined the overlap of the RAR $\gamma$ cistrome with 

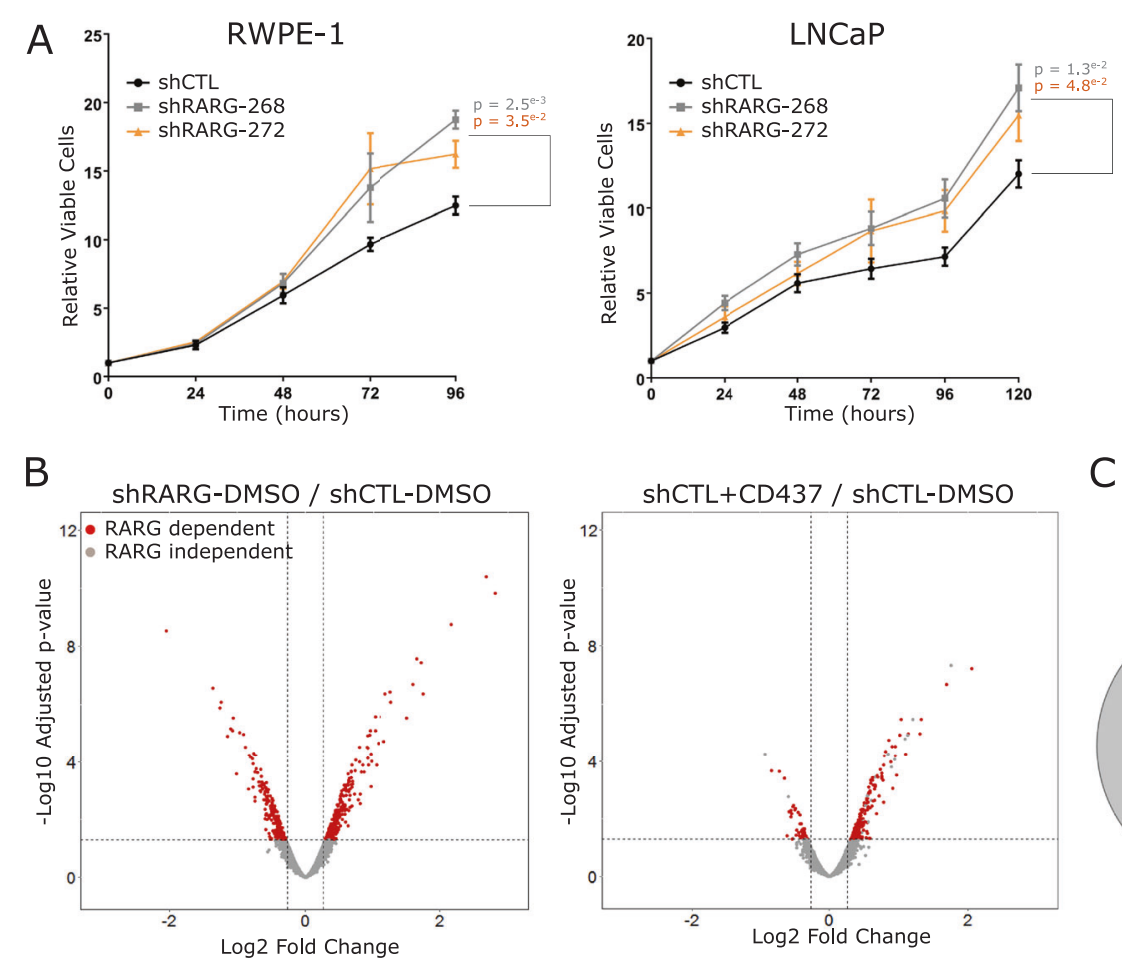

C
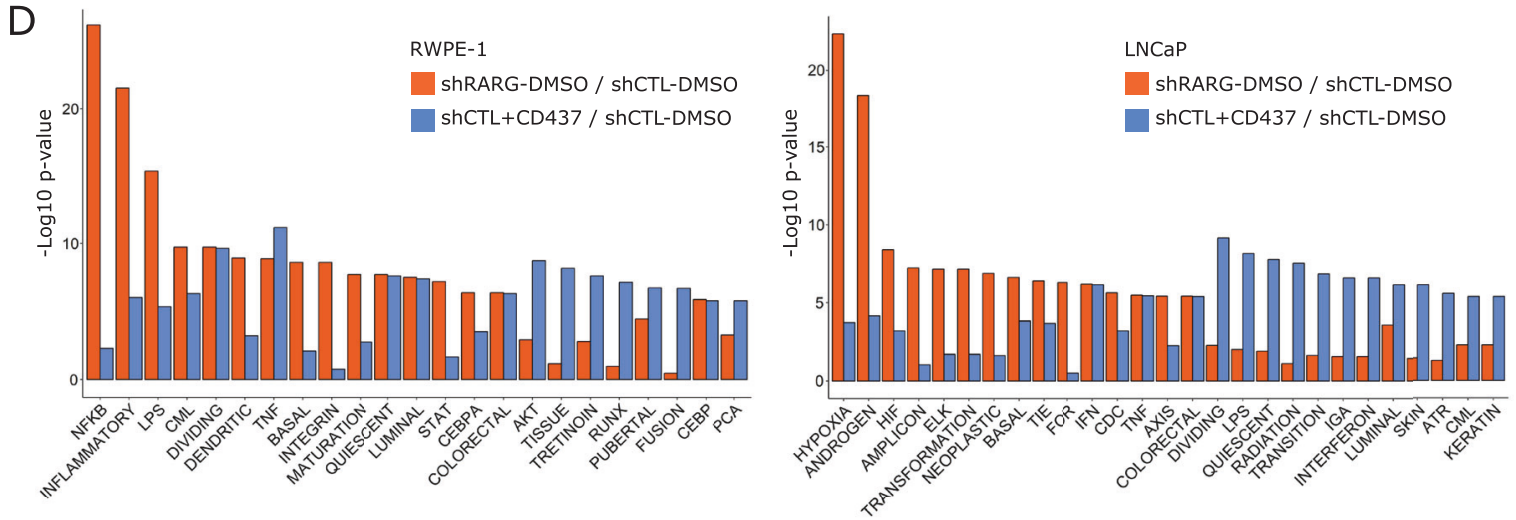

E

SENESE_HDAC1_AND_HDAC2_TARGETS_UP
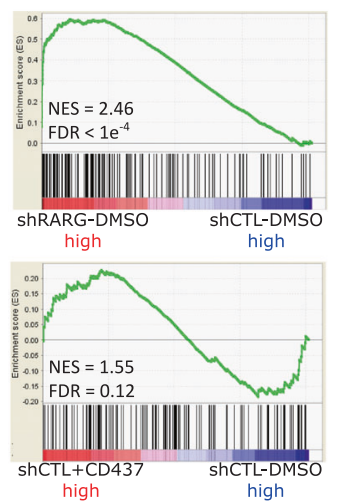

$\mathrm{F}$

MARTENS_TRETINOIN_RESPONSE_UP
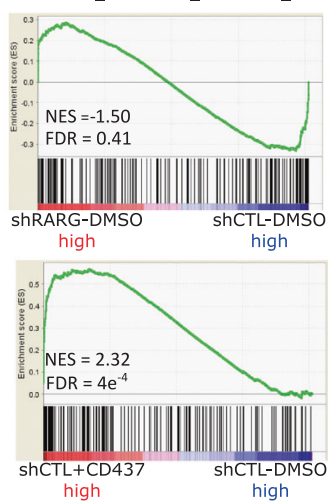

G
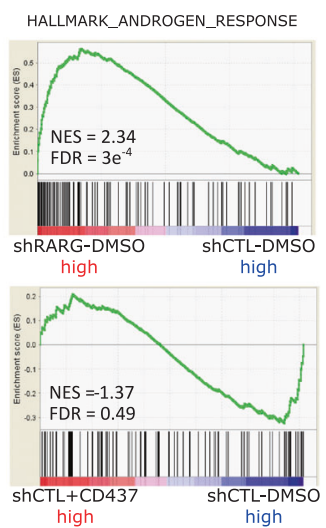

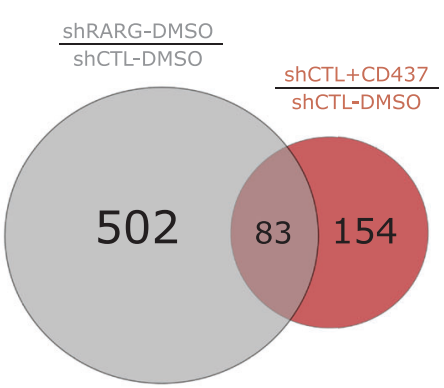

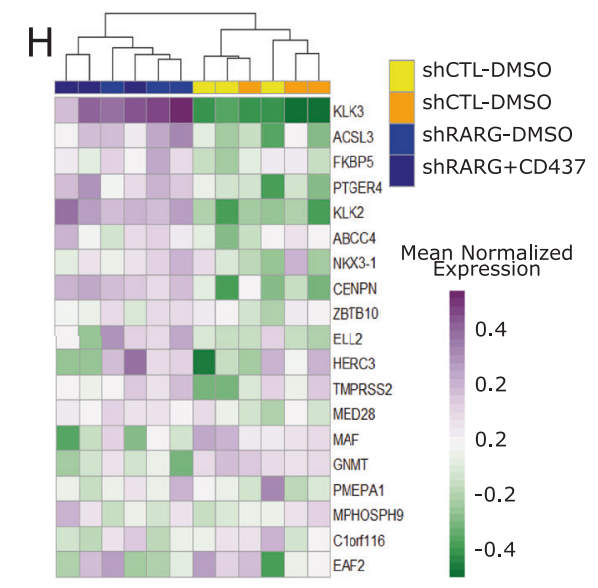

normal prostate epithelial cell enhancers derived from the FANTOM consortium [20]. Secondly, the overlap was measured between the RAR $\gamma$ cistrome and other nuclear receptors (AR, vitamin D receptor (VDR), ER) and NF- $\kappa B$ [2], derived in LNCaP cells, as well as AR and ER $\alpha$ derived in $\mathrm{VCaP}$ cells (Fig. 4a-c). 
Fig. $3 \operatorname{RAR} \gamma$ expression levels impact cell viability and gene expression in prostate cells. a Time-dependent measurements of cellular levels of ATP, as an indicator of cell viability, of each of the stable shRARG clones compared to vector controls in RWPE-1 (left) and LNCaP (right) cells. Each measurement was performed in biological triplicate, in triplicate wells. Significance of differences between viability of control and RAR $\gamma$ knockdown cells at the end of each study is noted. b Cells were treated in triplicate with CD437 (RWPE-1, $10 \mathrm{nM}$; LNCaP, $250 \mathrm{nM}, 24 \mathrm{~h}$ ) or DMSO vehicle control and gene expression was profiled using Illumina microarray (Illumina HT12v4) using DESeq2. Volcano plots depicting expression changes upon RAR $\gamma$ knockdown or in response to exogenous RAR $\gamma$ specific ligand (CD437) in RWPE-1 cells. Dotted lines indicate DEG thresholds ( $p$. $\operatorname{adj}<0.05$, fold change of \pm 1.2 ), and red dots represent RAR $\gamma$ dependent DEGs. Genes regulated by exogenous ligand were calculated as those that were differentially expressed in shCTL cells treated with ligand (shCTL+CD437/shCTL-DMSO) and not in shRARG cells treated with CD437. c Venn diagram depicting number of determined DEGs associated with reducing RAR $\gamma$ expression levels, and those from adding exogenous ligand. d Summary of significantly enriched pathways from gene set enrichment analyses (GSEA) (NES $>1.8$, FDR $q . v a l<0.05$ ) associated with reducing RAR $\gamma$ expression levels, and those from adding exogenous ligand in RWPE-1 (left) and LNCaP (right) cells. The top enriched meta-groups among significant GSEA sets are indicated. e, f Examples of top significant GSEA pathway enrichments observed in RWPE-1 cells and $\mathbf{g}$ in LNCaP cells. $\mathbf{h}$ Heatmap depicting the relative expression of a panel of androgen response genes defined previously by the TCGA consortium to reflect AR signaling [61]. Unsupervised hierarchical clustering of the gene expression patterns of these AR-regulated genes separated shRARG from shCTL cells

In the first instance, we used hypergeometric testing to examine the extent and significance of the overlaps between RAR $\gamma$ and other cistromes. In the absence of exogenous retinoid ligand, the RAR $\gamma$ cistrome significantly overlapped with regions in RWPE-1 cells that were occupied with $\mathrm{H} 3 \mathrm{~K} 27 \mathrm{ac}$ and H3K4me1 marks associated with enhancer status (Fig. 4a, left). Additionally, substantial enrichment of $\operatorname{RAR} \gamma$ binding was also observed at regions upstream yet proximal of expressed transcription start site (TSS) loci associated with high levels of $\mathrm{H} 3 \mathrm{~K} 4 \mathrm{me} 3$ (Fig. 4a, right). Specifically, 829/1256 RAR $\gamma$ binding sites overlapped with the combined H3K27ac, H3K4me1 and DNase cistromes, also from RWPE-1, suggesting that, in the absence of exogenous retinoid ligand, $\operatorname{RAR} \gamma$ is commonly found in open chromatin active enhancer regions; the significance of overlaps is shown (Fig. 4b, c). Reflecting the RAR $\gamma$ transcriptomic data, the $\operatorname{RAR} \gamma$ cistrome significantly overlapped with LNCaP AR data sets [21], and DHT-dependent and TNF-stimulated p65 cistrome [2] (Fig. 4c). By contrast, there was no significant overlap between the RAR $\gamma$ cistrome and either AR, VDR or an ETS transcription factor (ERG) binding in the TMPRSS2-ERG fusion-positive $\mathrm{VCaP}$ cell line.

RAR $\gamma$ binding at active enhancer regions was also supported by ChromHMM states derived in RWPE-1 cells showing binding of $\mathrm{RAR} \gamma$ at sites flanking transcription sites. An example of this is shown for the KRT15 gene where the location of the binding site is unambiguously related to the gene (Fig. 4d).

Next, we sought to dissect transcriptome-cistrome relationships. In the first instance, candidate-level relationships were tested. For example, in the absence of exogenous retinoid ligand expression of KRT15 was both significantly reduced by the knockdown of $\operatorname{RAR} \gamma\left(p=5.1 \mathrm{e}^{-6}\right)$ and induced by CD437 $\left(p=2.3 \mathrm{e}^{-3}\right)$ (Fig. 4e). To test the genome-wide level of significance in transcriptome-cistrome relationships, both in the absence and presence of exogenous retinoid ligand, $\operatorname{RAR} \gamma$ cistromes were annotated to within $7.5 \mathrm{~kb}$ of known gene TSS locations. The absolute magnitude of differential expression upon stable RAR $\gamma$ knockdown of these cistrome proximal genes was compared with that of all expressed genes in RWPE-1 cells (Fig. 4f, left). To test the associations between RAR $\gamma$ binding and RAR $\gamma$-dependent change in gene expression, we used a random sampling with replacement, or bootstrapping approach, as developed previously [22] (Supplementary Table 1). This approach revealed that RAR $\gamma$ cistromeassociated genes were significantly more differentially regulated upon knockdown of $\operatorname{RAR} \gamma$ than would be predicted by chance $\left(p \cdot \operatorname{emp}=1 \mathrm{e}^{-5}\right)$, supporting a functional relationship between RAR $\gamma$ binding and expression control. A similar observation was made regarding CD437-regulated expression and CD437-dependent RAR $\gamma$ cistromeassociated genes ( $p . e m p=1 \mathrm{e}^{-5}$ ) (Fig. 4f, right).

Next, we tested the expression relationships of RAR $\gamma$ and the RAR $\gamma$-annotated genes in the TCGA-PRAD and MSKCC cohorts. We used Kolmogorov-Smirnov test to examine whether the distribution of correlations between expression of $R A R G$ with experimentally derived $\operatorname{RAR} \gamma$ annotated genes deviated significantly from that of its correlation with all genes. In the TCGA-PRAD and MSKCC cohorts the correlation between RAR $\gamma$ and $\operatorname{RAR} \gamma$-annotated genes was significantly more positive than predicted by chance (Supplementary Figure 4A), again suggesting functional relationships between RAR $\gamma$ and its target genes.

Finally, we filtered RAR $\gamma$-annotated genes (altered by greater than $\pm 2 Z$ scores in more than $35 \%$ tumors relative to normal tissue) and identified 58 genes. Unsupervised hierarchical clustering of the gene expression patterns identified distinct clusters of patients (Fig. 4g) and distinguished a cluster of patients with high Gleason grade tumors (after adjusting for age; $p$ value $=0.038$ ). We also reasoned that higher Gleason grade tumors were associated with worse outcome and therefore we tested relationships between the expression of individual genes and disease-free survival. After FDR correction, four of these genes were individually significantly associated with disease-free survival, including the steroidogenic enzyme CYP11A [23] 


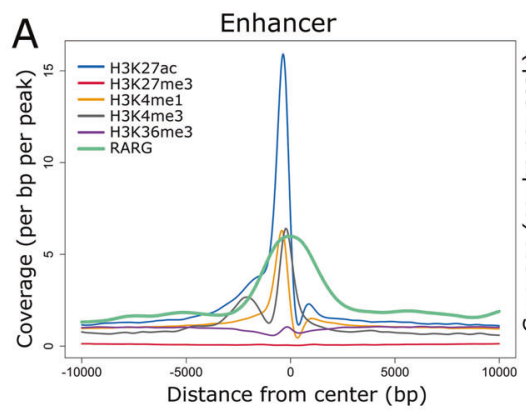

C

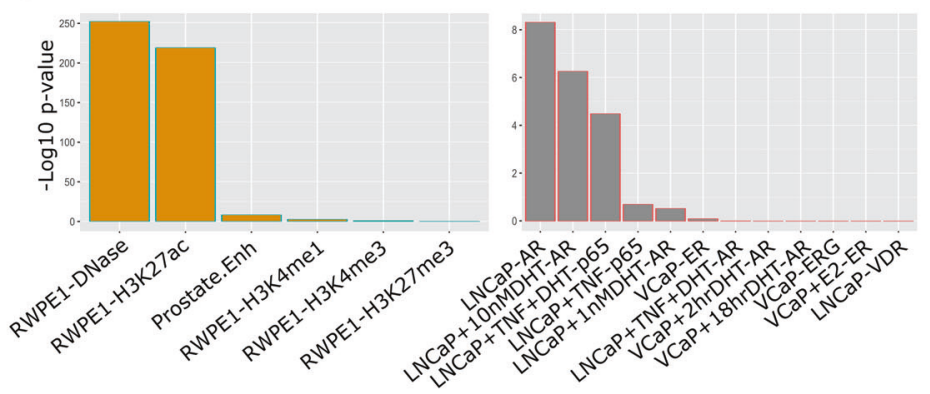

D
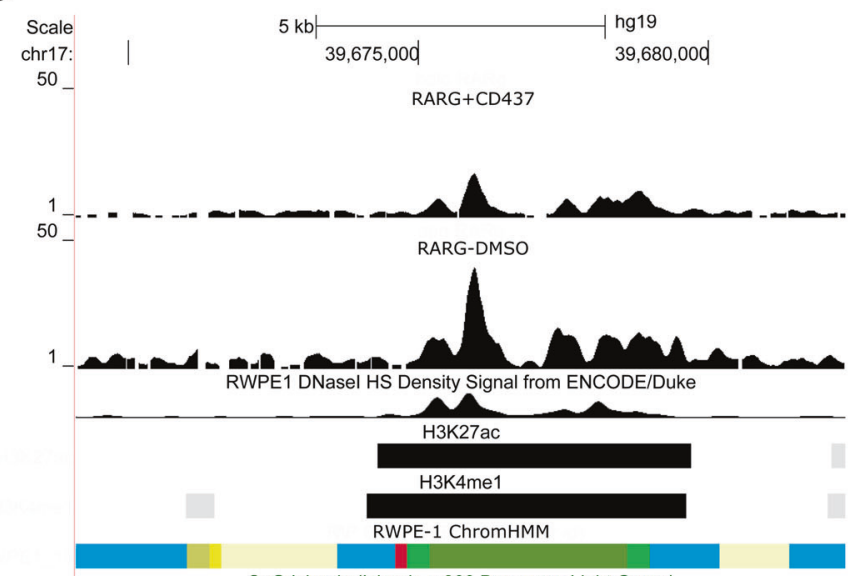

CpG Islands (Islands < 300 Bases are Light Green)

UCSC Genes (RefSeq, GenBank, CCDS, Rfam, tRNAs \& Comparative Genomics)

KRT15

C. K

\section{F}

$\mathrm{F}_{\text {ShRARG-DMSO / ShCTL-DMSO }}$

Background $=0.134$

RARG bound $=0.215$

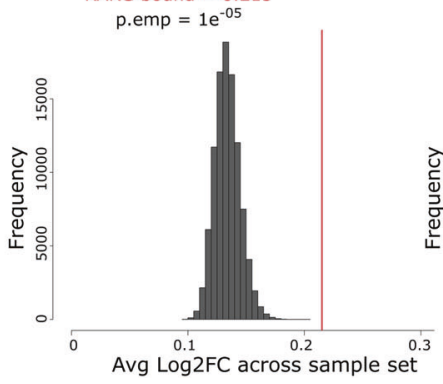

shCTL+CD437 / shCTL-DMSO

Background $=0.113$

RARG bound $=0.354$

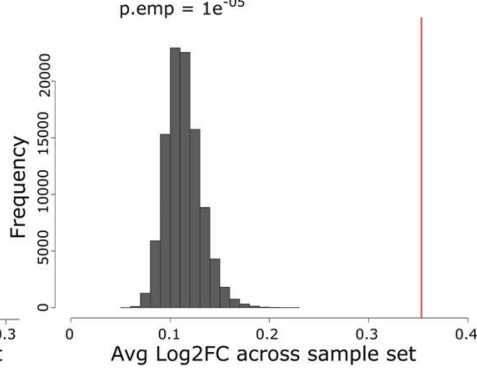

B

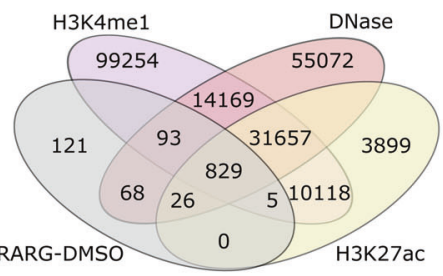

E

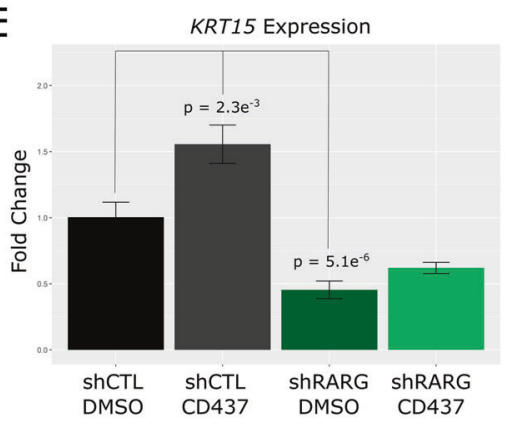

G

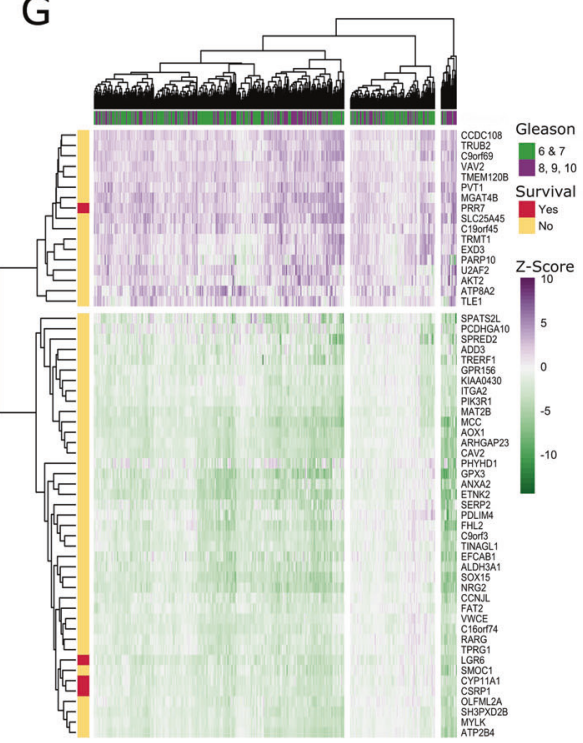

$\mathrm{H}$

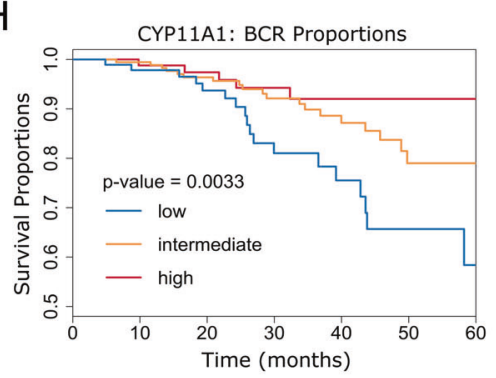


Fig. 4 The RAR $\gamma$ cistrome is enriched at active enhancers of genes that are also enriched for androgen receptor binding and associate with aggressive prostate cancer. Stable transfection of a bacterial artificial chromosome containing a fusion $R A R G-E G F P$ gene transcribed from the endogenous $R A R G$ promoter was undertaken to generate RWPE-1RARG-EGFP clones. Stably expressing RAR $\gamma$-EGFP RWPE-1 cells were treated in triplicate with either CD437 $(10 \mathrm{nM}, 2 \mathrm{~h})$ or vehicle (DMSO), and subjected to ChIP-Seq undertaken with an EGFP antibody. a Significant RAR $\gamma$ ChIP-seq peaks $(p . a d j<0.1)$ were determined with Rsubread and csaw. Cross-profiling of significant RAR $\gamma$ ChIP-seq peaks and the indicated histone modifications also from RWPE-1 (GSE63094) at genomic loci performed using annotatePeaks available from the HOMER (Hypergeometric Optimization of Motif EnRichment) suite. Genomic profiles are centered at enhancer regions (overlapping of H3K27ac and H3K4me1) (left), and TSS loci of all expressed genes in RWPE-1 (right). b Overlap of unstimulated RAR $\gamma$ binding peaks with select publicly available epigenetic data sets from RWPE-1 cells was determined with ChIPpeakAnno using a maximum gap of $500 \mathrm{bp}$; H3K4me1 and H3K27ac (GSE63094) and DNase sensitivity (GSM1541008). c The negative $\log 10$ ( $p$ values) of the overlaps between data sets determined with ChIPpeakAnno were visualized for RAR $\gamma$ binding peaks and a wider panel of publicly available data; prostate enhancers (FANTOM), LNCaP AR (GSE48308), VCaP AR (GSE84432), ER $\alpha$ (GSE43985) and LNCaP NF-kB (GSE83860) cistromes. d Representative RAR $\gamma$ binding site upstream of the KRT15 TSS showing coincident binding with H3K4me1 and H3K27ac in RWPE-1 cells. The ChromHMM (grass green $=$ low transcription; bright green $=$ active enhancer; red $=$ transcriptional enhancer; blue $=$ active TSS; pale yellow $=$ poised transcription; yellow $=$ poised enhancer), $\mathrm{CpG}$ island and DNase sensitivity tracks are also shown. e The impact of RAR $\gamma$ knockdown on KRT15 expression from expression profiling in RWPE-1 cells by microarray (Fig. 1). f Bootstrapping approach (using boot) to test the statistical strength of relationships between genes annotated to be bound by RAR $\gamma( \pm 7.5 \mathrm{~kb}$ from the TSS) and those modulated by $\mathrm{RAR} \gamma$ knockdown (left) or in the presence of CD437 ligand (right) in RWPE- 1 cells. The red line is the mean observed fold change for the indicated gene set derived from the microarray data (Fig. 1) and the distribution is simulated data from the same dataset. The significance between the observed and simulated expression of the same number of genes is indicated. $\mathbf{g}$ Expression heatmap of annotated RAR $\gamma$ cistrome genes in the TCGA-PRAD cohort (pheatmap). Genes were filtered to identify those that were altered by more than $\pm 2 Z$ scores in $35 \%$ of tumors relative to normal samples. Unsupervised hierarchical clustering grouped tumors that significantly distinguished higher Gleason Grade (Gleason >7), after adjusting for age (Pearson's Chi-squared test $\mathrm{X}^{2}=51.187, \mathrm{df}=35$ ). For each gene, Kaplan-Meier curves (survival) were generated as time to tumor recurrence, indicated by biochemical progression, and those genes which identify significantly ( $p$.adj $<0.1)$ shorter disease-free survival are indicated. $\mathbf{h}$ Illustrative Kaplan-Meier curve for CYP11A1 expression depicting the significantly reduced time to 5 -year biochemical recurrence post radical prostatectomy

(Fig. 4h); LGR6, a WNT regulator [24] and implicated in breast cancer; and PRR7, a central regulator of CLOCK.

\section{Reduced RARy expression alters AR signaling capacity and sensitivity}

Combined, the RAR $\gamma$ knockdown phenotype, transcriptome and cistrome data support the concept that in the absence of exogenous retinoid ligand $\mathrm{RAR} \gamma$ functions are substantially intertwined with other TFs including the AR. Therefore, we sought to test the genome-wide impact of RAR $\gamma$ expression on AR function directly in non-malignant prostate epithelial HPr1-AR cells.

Again, generating stable RAR $\gamma$ knockdown reduced RAR $\gamma$ levels by $60-80 \%$, while RAR $\alpha$ and RAR $\beta$ remained unaffected, which was not altered by DHT treatment (Supplementary Figure 5A-E). HPr1-AR cells constitutively express AR and undergo androgen-induced differentiation from a basal-like phenotype towards a more luminal-like phenotype concomitant with inhibition of proliferation [25]. Stable RAR $\gamma$ knockdown changed the anti-proliferative response induced by DHT, which was significantly dampened in RAR $\gamma$ knockdown HPr1-AR cells (Fig. 5a).

We therefore investigated whether, in the absence of exogenous retinoid ligand, RAR $\gamma$ functions govern AR signaling. We tested this globally through RNA-Seq profiling of RAR $\gamma$ knockdown HPr1-AR cells treated with DHT. Analyses confirmed strong reduction in $R A R G$ levels, being the most significantly repressed gene when comparing RAR $\gamma$ knockdown HPr1-AR to control cells (Supplementary Figure 5E, Fig. 5b). Indeed, at the transcriptome level, RAR $\gamma$ knockdown substantially reduced the sensitivity of the DHT-dependent transcriptome at both 24 and $96 \mathrm{~h}$ of exposure (Fig. 5b, c, Supplementary Figure 6A-C). For instance, we tested the mean of the log fold change between the two states and revealed that at $24 \mathrm{~h}, 1454$ of the 2309 (63.0\%) DHT-regulated DEGs were either significantly less induced (Fig. 5b, purple) or significantly less repressed (Fig. 5b, green, $p \cdot a d j<2 e-16$ ). Among those genes with the greatest shift in sensitivity included several established AR targets and AR pathway interacting genes including TMEM37, MRAS, ILIA and ANXA1. This shift in sensitivity was almost uniformly directional, as in almost all cases there was a dampening effect for both induced and repressed genes. For example, TMEM37 is strongly induced by DHT, and RAR $\gamma$ loss significantly dampens this induction (Fig. 5f), whereas ANXAl was repressed by DHT, but to a lesser extent upon RAR $\gamma$ loss.

To this point, the switch in the sensitivity response to RAR $\gamma$ loss was generally a reduction of DHT regulation. However, the capacity of DHT regulation was also shifted, albeit to a lesser extent, as a small number of genes (109) gained unique DHT regulation following RAR $\gamma$ knockdown in HPr1-AR cells at $24 \mathrm{~h}$ (Fig. 5c). Thus, RAR $\gamma$ knockdown substantially impacts the sensitivity of the AR-regulated transcriptome and appears to have a more modest impact on the capacity of the AR-regulated transcriptome.

GSEA on the AR-regulated transcriptome in control and RAR $\gamma$ knockdown cells revealed pathways that were selectively disrupted by RAR $\gamma$ knockdown (Fig. 5d, e). High enrichment for androgen response, MYC and 

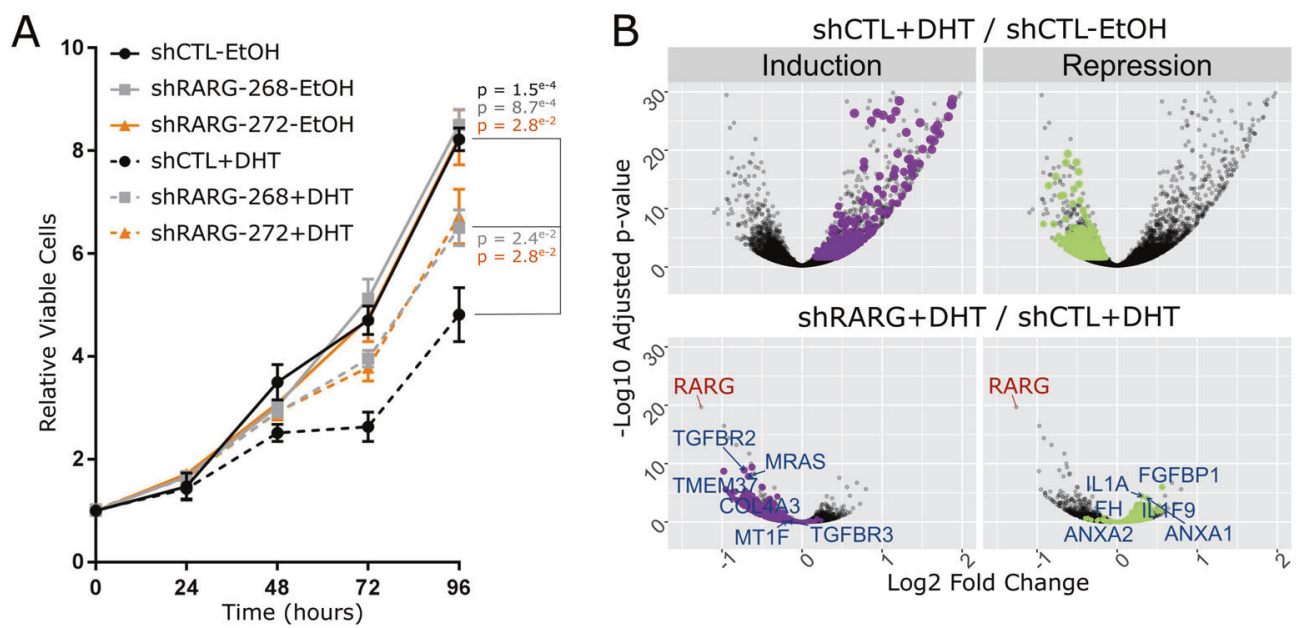

C

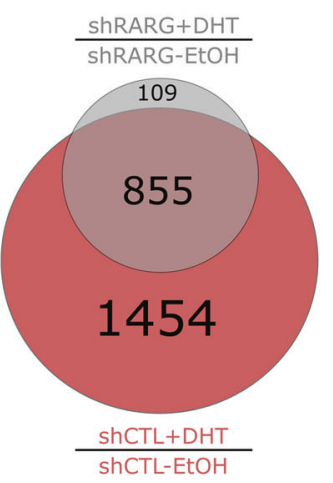

D

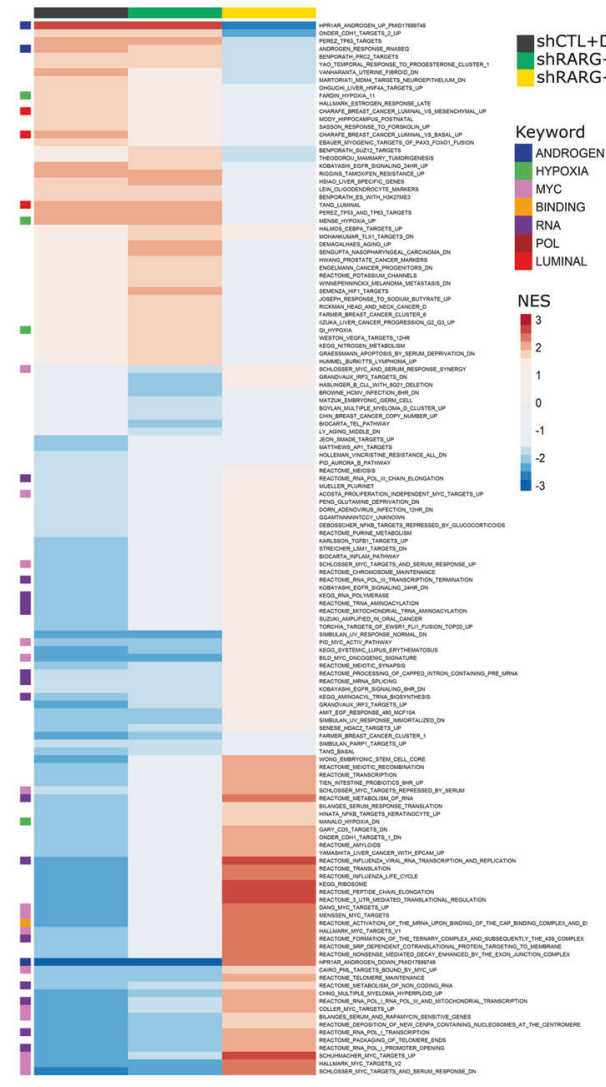

E BOLTON_HPR1AR_DHT_UP
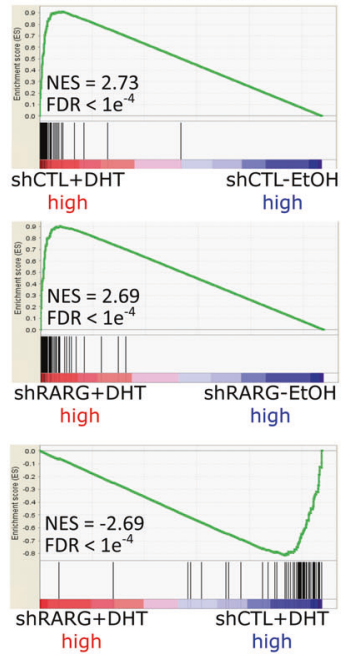

F

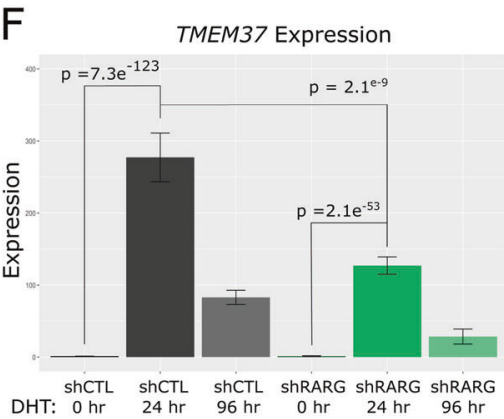

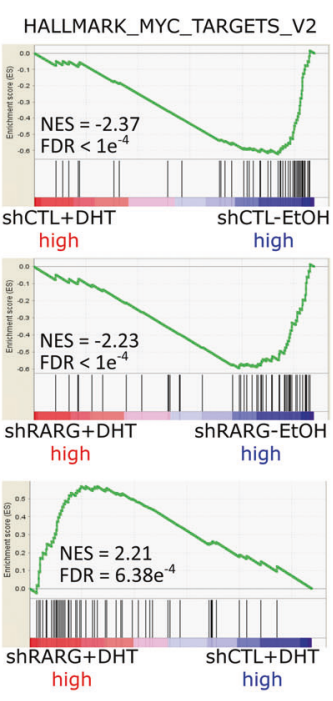

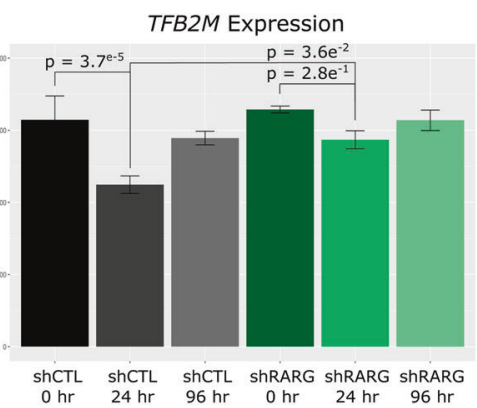

hypoxia-associated pathways [25] were clear upon DHT exposure in control cells and are consistent with a shift towards luminal differentiation and an anti-proliferative response to DHT. In RAR $\gamma$ knockdown cells the extent of AR pathway regulation, both induction and repression events, by DHT was significantly reduced (Fig. 5d). For example, an established HPr1-AR androgen response pathway (Fig. 5e, left) was highly elevated in DHT treated relative to untreated control cells $(\mathrm{NES}=2.73$, upper panel), and while still elevated in treated RAR $\gamma$ knockdown cells $(\mathrm{NES}=2.69$, middle panel), the extent of this induction was substantially dampened $(\mathrm{NES}=-2.69$, lower panel). Conversely, repression of MYC regulated pathways (Fig. 5e, right) was apparent in treated control cells (NES = -2.37 , upper panel) and while still apparent in RAR $\gamma$ knockdown cells (NES $=-2.23$, middle panel), the extent of repression was also reduced (NES $=2.21$, lower panel). Interestingly, a prominent RAR $\gamma$ binding peak was identified in an enhancer region upstream of MYC (Supplementary Figure 6D). Candidate examples from androgen 
Fig. 5 RAR $\gamma$ governs androgen-induced responses in non-malignant HPr1-AR prostate epithelial cells. HPr1-AR cells were stable transfected with shRNA to RARG and the response to DHT measured. a Cell viability of HPr1-AR-shCTL and HPr1-AR-shRARG cells in the absence or presence of $10 \mathrm{nM}$ DHT was measured for up to $96 \mathrm{~h}$. Significance of differences between triplicate experiments between viability of indicated experimental groups at the end of the study is noted. b HPr1-AR-shCTL and HPr1-AR-shRARG cells were treated in triplicate with DHT or vehicle control for $24 \mathrm{~h}$ and gene expression profiled via RNA-seq and analyzed with Rsubread/DESeq2. Volcano plot depicting DHT-induced gene expression changes in HPr1-ARshCTL cells (top). Highlighted genes represent those that display induction (purple) or repression (green) in response to DHT in HPr1AR-shCTL expression, and which were significantly dampened in HPr1-AR-shRARG cells (bottom); 6 genes are labeled that had the greatest magnitude of dampened response, including a loss in induction of TMEM37 and a loss of repression of FGFBP1. c Venn diagram representing the number of DEGs determined after DHT treatment in HPr1-AR-shCTL and HPr1-AR-shRARG cells. Specifically, 1454 of the $2309\left(63.0 \%\right.$, hypergeometric $p$ value $\left.<2 \mathrm{e}^{-16}\right)$ DHT-regulated DEGs were either significantly less induced or had significantly reduced repression in shRARG cells. d Heatmap depicting normalized enrichment scores (NES) of all enriched pathways related to DHT treatment in different comparisons (NES > 1.8, FDR $q$-value $<0.05$ ). Select meta-groups from keyword enrichment analysis are depicted. e Example of top significantly upregulated (left) and downregulated (right) GSEA pathways upon DHT treatment. Enrichments are shown for each comparison, as well as (f) an expression profile of a representative gene from each gene set (left, TMEM37, right TFB2M)

response (TMEM37) and MYC-associated (TFB2M) pathways are shown (Fig. 5f) to illustrate the shift in AR sensitivity observed upon RAR $\gamma$ loss.

Together, these data suggest that RAR $\gamma$ expression significantly regulates AR function in normal prostate cells independently of exogenous retinoid ligand. Specifically, RAR $\gamma$ loss impacts both phenotypic and transcriptomic androgen responses which manifest as a dampened response to DHT that normally slows proliferation and induces differentiation.

\section{Elevated miR-96 drives reduced RAR $y$ expression and associates with aggressive prostate cancer}

The frequent downregulation of $R A R G$ reflected neither mutation nor copy number variation [7] and therefore we considered epigenetic mechanisms. In the first instance we assessed DNA methylation data available in TCGA-PRAD cohort, but found no evidence for altered methylation at $R A R G$ TSS loci, although we found stronger evidence for increased $\mathrm{CpG}$ methylation associated with the paralogs RAR $\alpha$ and notably RAR $\beta$ (Supplementary Figure 7). Therefore, we considered miRNA that may target RAR $\gamma$, and used in silico prediction tools [26] to define a cohort of miRNAs that target the commonly downregulated NRs (e.g., $R A R G, G R$ ) that we previously identified in the TCGA-PRAD and MSKCC cohorts [7].
Specifically, 61 putative NR-targeting miRNAs were identified (Supplementary Figure 8). We used a bootstrapping approach to test if these 61 miRNAs were altered at the level of expression in PCa cohorts. Collectively, these 61 miRNAs were more significantly elevated in PCa samples than predicted by chance $(p \cdot a d j=0.02)$ and were reciprocal to the reduction of NR mRNA expression [7]. The miR-96-182-183 cluster was among the most commonly upregulated miRNAs. Although similar, base substitutions in the targeting regions of each miRNA suggest unique functionality (Supplementary Figure 9A). Only miR-96 and miR-182 have predicted target sequences in the $R A R G 3^{\prime}$ untranslated region (UTR) (Supplementary Figure 9B).

In both the MSKCC and TCGA-PRAD cohorts, $R A R G$ significantly and negatively correlated with miR-96-182183 cluster members, but most strongly with miR-96 (Fig. 6a). Expression analyses in a panel of prostate cell lines (Fig. 6b) revealed miR-96 was elevated and $R A R G$ reduced relative to non-malignant RWPE-1 and HPr1-AR cells in all $\mathrm{PCa}$ cell lines examined. Profiling in PCa mouse models revealed reduced Rarg in both Pten $^{-1-}$ model [27] and to a greater extent in the TRAMP model [28] but not in HiMYC mice [29] relative to wild-type mice (Supplementary Figure 10A). Indeed, Rarg expression decreased with PCa development in TRAMP mice relative to age-matched wildtype controls (C57BL/6), and inversely correlated most significantly with elevated miR-96 expression (Pearson's $r$ $=-0.88$ ) (Fig. 6c, Supplementary Figure 10B). Furthermore, in the TRAMP model, significant expression changes were observed as early as 10 weeks of age, when the mice display prostate epithelial hyperplasia. Finally, the expression changes of $R A R G$ and miR-96 cluster members were validated in an independent cohort of 36 matching tumor/ normal prostate tissue pairs obtained from Roswell Park, corroborating observations in TCGA-PRAD and MSKCC cohorts that furthermore associated with Gleason sum (Supplementary Figure 11A, B). Additionally, miR-96 expression in the TCGA-PRAD cohort associated with Gleason sum and clinical stage (Supplementary Figure 11C) and stratified patients based on shorter disease-free survival $(p=0.018$, Supplementary Figure 11D). Together, these findings in murine and human prostate tissues suggest that increased miR-96 expression occurs early and is sustained in PCa development, correlates strongly with loss of $R A R G$ and associates with aggressive PCa outcomes.

Two miR-96 recognition elements were identified in the $R A R G$ 3'UTR region (Supplementary Figure 9B). Ectopic overexpression of miR-96 resulted in significant loss of RAR $\gamma$ mRNA and protein in both RWPE-1 and LNCaP cells (Fig. 6d, Supplementary Figure 12A-C). To demonstrate miR-96 interacts directly with RARG we developed and transfected a $R A R G 3^{\prime} \mathrm{UTR}$ containing luciferase vector 

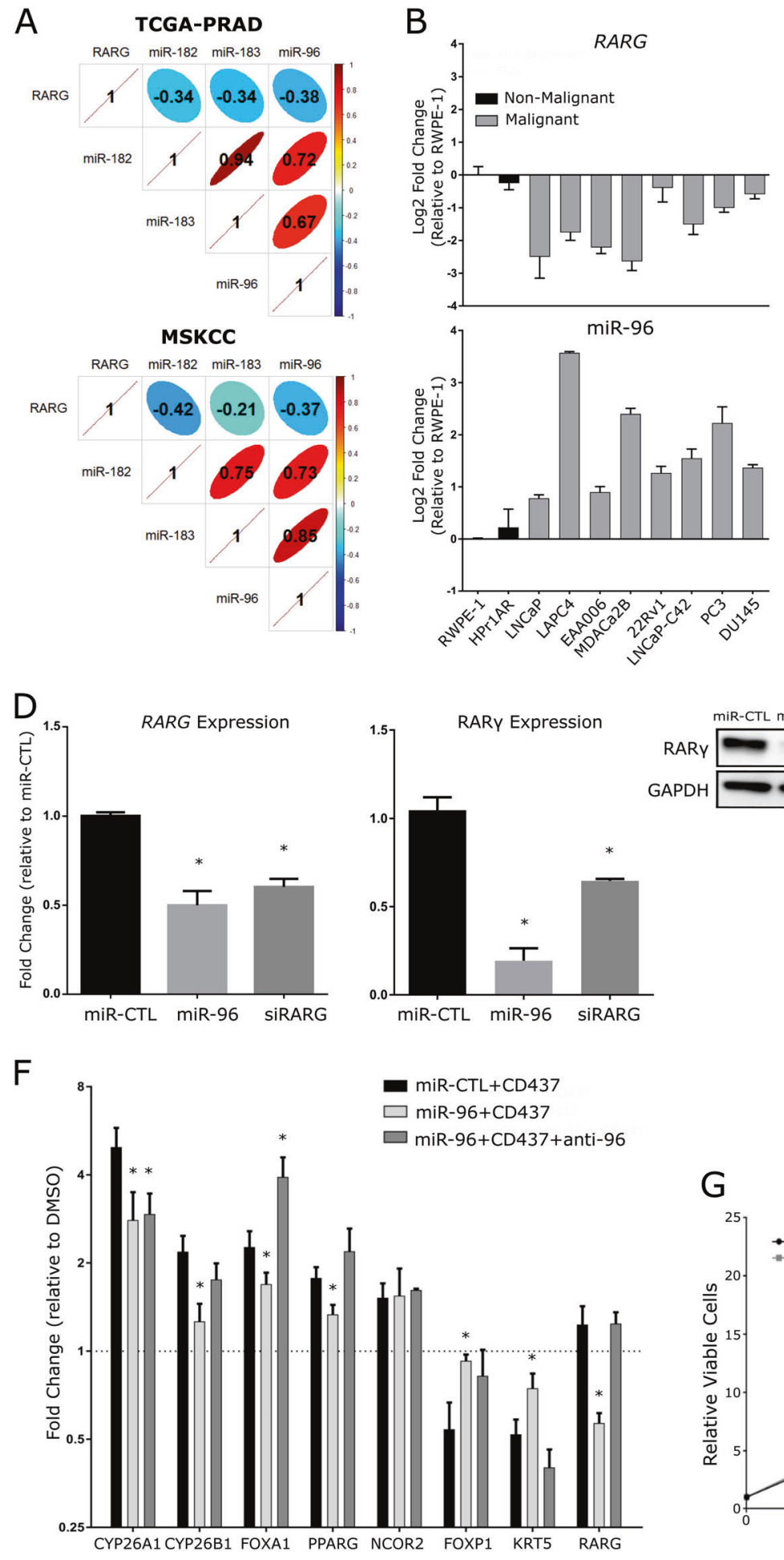

into cells and measured a significant reduction in luciferase activity with the addition of exogenous miR-96 mimic (Fig. 6e). Next we tested how miR-96 modulated the RAR $\gamma$ ligand-dependent induction and repression of target genes previously identified (Fig. 6f). Indeed, 6 out of 7 CD437induced (CYP26A1, CYP26B1, FOXA1, PPARG) or
C

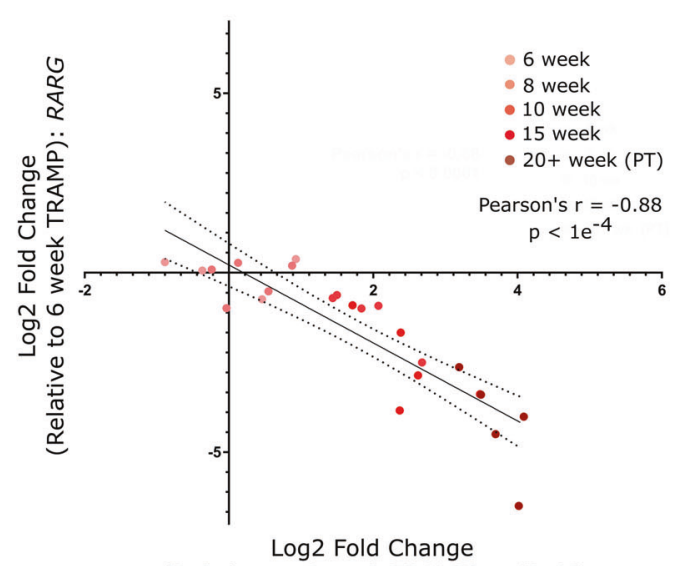

(Relative to 6 week TRAMP): miR-96
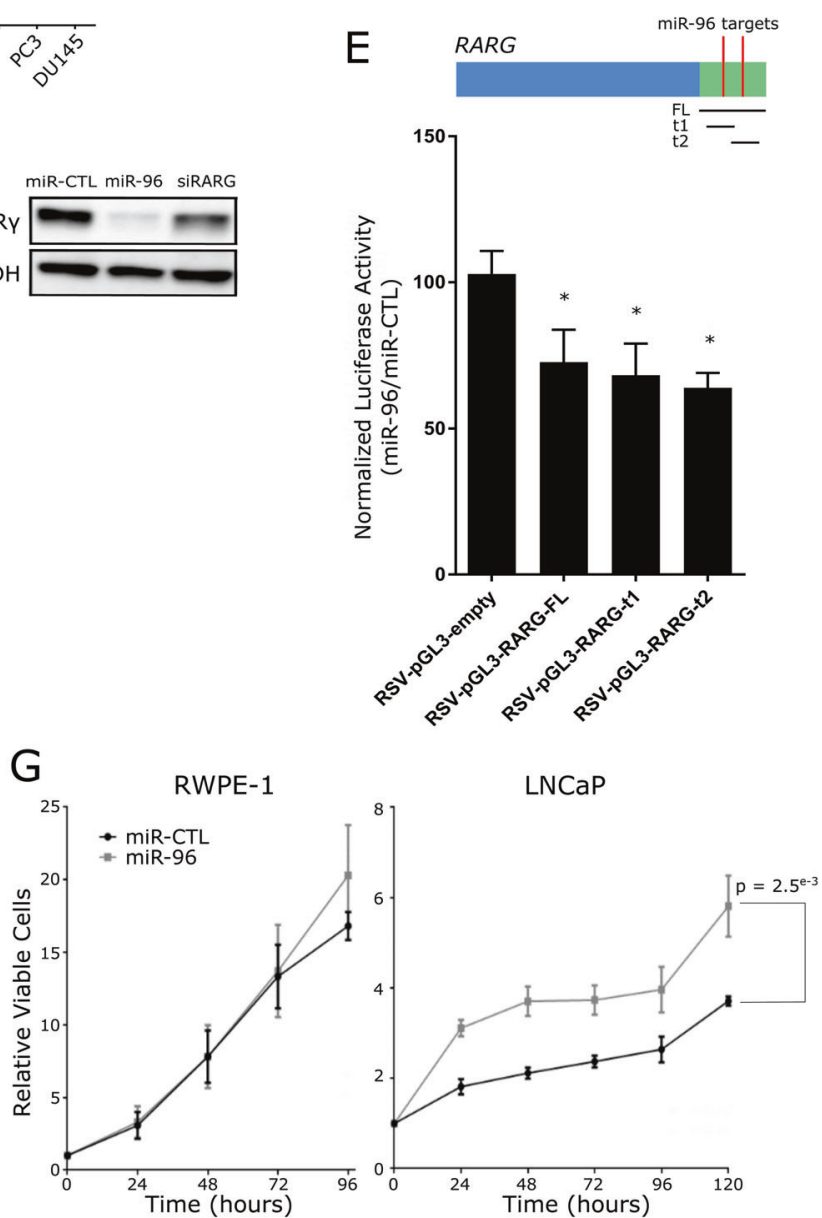

repressed (FOXP1, KRT5) genes were significantly dampened by the presence of miR-96, suggesting a reduction in RAR $\gamma$ sensitivity. Furthermore, we found that antagomiR96 treatment in combination with miR-96 mimic rescued expression of $R A R G$, and thus rescued $\mathrm{RAR} \gamma$ regulation in almost all cases. Finally, we tested how miR-96 
Fig. 6 MicroRNA-96 directly targets and regulates $R A R G$ in prostate cells. a Cross-correlation matrices depicting the relationships between $R A R G$ and miR-96 cluster member expression in PCa samples from MSKCC and TCGA-PRAD cohorts (corrplot). b Relative expression of miR-96 (bottom) and RARG (top) across 10 prostate cell lines representing different stages of PCa progression. The cell models examined comprised immortalized RWPE-1 and HPr1-AR nonmalignant prostate epithelial cells, LNCaP, LAPC4 and EAA006 androgen-sensitive PCa cells, MDAPCa2b, 22Rv1 and LNCaP-C42 CRPC cells, as well as PC3 and DU145 cells derived from distant metastases. c Correlation analyses of $R A R G$ with miR-96 expression over the course of palpable tumor (PT) development in TRAMP. The strength and significance of the correlation is indicated. Tumors from 5 mice were examined at each time point and compared to the mean of 10 6-week-old wild-type mice; 2 6-week tumors were dropped due to technical failure to generate high-quality RNA. d $R A R G$ mRNA (left) and RAR $\gamma$ protein expression (right) in RWPE- 1 cells after $48 \mathrm{~h}$ of transfections with miR-96 mimics or siRNA targeting $R A R G$. Significance of difference between targeting and control cells are noted $(* p<0.05)$. e Luciferase assay assessing direct targeting of miR-96 to the full-length (FL) RARG $3^{\prime}$ UTR or individual predicted target sites $(\mathrm{t} 1, \mathrm{t} 2)$ within the RARG $3^{\prime} \mathrm{UTR}$. Either miR-96 or miR-CTL mimics $(30 \mathrm{nM})$ were transfected into RWPE-1 cells for $48 \mathrm{~h}$ along with indicated RSV-pGL3 constructs and pRL-CMV Renilla luciferase expressing vectors, and luciferase activity measured by Dual-Glo Luciferase Assay System in triplicate. Significance of difference between luciferase construct with and without $R A R G 3^{\prime} \mathrm{UTR}$ sequences cells are noted $(* p<0.05)$. f RWPE- 1 cells were pretreated with miR-CTL, miR-96 mimic ( $30 \mathrm{nM})$, or combination of miR-96 mimic and antagomiR-96 for $48 \mathrm{~h}$ prior to CD437 exposure $(10 \mathrm{nM})$ for $24 \mathrm{~h}$, and candidate transcripts measured by RT-qPCR in triplicate. Induction relative to untreated control for each condition is shown, and significance of CD437 induction/repression between miR-CTL and miR-96 groups are indicated $(* p<0.05)$. $\mathbf{g}$ Cell viability of RWPE-1 (left) and $\mathrm{LNCaP}$ (right) cells for up to $120 \mathrm{~h}$ post transfection with either miR-96 or non-targeting control (NC) mimics was measured in triplicate. Significance of differences between viability of indicated experimental groups at the end of the study is noted

overexpression impacted ATRA regulation of a previously identified [17] RAR $\gamma$ target gene, transglutaminase 4 (TGM4). The induction of TGM4 was dampened by both short interfering RNA (siRNA) targeted to RAR $\gamma$ and miR96 mimic (Supplementary Figure 13B).

The impact of miR-96 overexpression on cell viability and cell cycle distribution was tested. Transfection with miR-96 mimics led to a significant increase in viability of LNCaP cells $\left(p=2.5 \mathrm{e}^{-3}\right)$ (Fig. $6 \mathrm{~g}$ ). These findings reflect phenotypes observed in RAR $\gamma$ knockdown cells, where reduced expression of the receptor associated with increased viability (Fig. 3). Exogenous miR-96 also altered the cell cycle distribution. In LNCaP cells there was also a loss of cells in $\mathrm{G}_{1} / \mathrm{G}_{0}$ phase $(53.2 \%$ relative to $64.8 \%$ ) and increase in $S$ and $G_{2} / M$ phases (Supplementary Figure 13A). Cell cycle shifts in LNCaP cells transfected with miR-96 mimics did not mirror those observed in RAR $\gamma$ knockdown cells, and furthermore no significant changes were noted in RWPE-1 cells, suggesting that miR-96-related phenotypes also involve additional gene targets other than RAR $\gamma$.
Together, these findings suggest elevated miR-96 is common in $\mathrm{PCa}$ and targets and suppresses $R A R G$ expression in order to dampen RAR $\gamma$ function, an interaction, which in mouse models at least, occurs early in PCa initiation. In $\mathrm{LNCaP}$ cells miR-96 mimics can increase viability and in PCa tumors miR-96 levels associate with higher Gleason score, clinical stage and predict disease recurrence.

\section{MiR-96 targets a network of RARy interacting co-factors}

While these data support miR-96 targeting of RAR $\gamma$, other studies have identified additional targets in prostate and other cancers including the pioneer factor FOXO1 [30-33]. Therefore, to identify all miR-96 targets (the miR-96 targetome) in an unbiased manner, we undertook a biotinmiRNA (bi-miR) capture and streptavidin pulldown approach coupled with microarray analyses [34]. Biotin labeling of miR-96 mimics did not interfere with either transfection or knockdown efficacy of target gene expression (Supplementary Figure 14A, B), and was able to capture known (e.g., RARG and FOXOl) and predicted (TBL1X) miR-96 targets (Supplementary Figure 14C).

In the first instance, processing of the bi-miR-96 and control mRNA libraries and principal component analysis revealed strong separation of experimental groups (Supplementary Figure 14D). Subsequently, comparing bi-miR96 pulldown to input RNA (fold change (FC) $>1.2, p$.adj $<$ 0.05 ) and to non-targeting control (bi-miR-CTL) pulldown revealed 111 and 389 miR-96 targets in RWPE-1 and LNCaP cells, respectively, which were largely shared, but also had unique genes (Fig. 7a, b, Supplementary Figure 14E). Among these targets, $3^{\prime} \mathrm{UTR}$ miR-96 target site motif (GTGCCAA) was the most highly enriched miRNA motif (Fig. 7c) (GSEA in LNCaP $p$.adj $=1.24 \mathrm{e}^{-26}$, RWPE-1 $p$. $\operatorname{adj}=1.70 \mathrm{e} 10^{-9}$ ), underscoring the efficacy of this method to capture miR-96 targets. Quantitative real-time reverse transcription-polymerase chain reaction (RT-qPCR) validation of bi-miR-96 capture methodology in LNCaP cells independently confirmed the capture of known and novel targets identified from profiling efforts (Supplementary Figure 15F).

The capacity of miR-96 to suppress target gene expression was also assessed by independent transfections of biotinylated and non-biotinylated miR-96 mimics. In LNCaP cells, 6 out of 7 identified miR-96 targets were significantly downregulated $48 \mathrm{~h}$ post miR-96 or bi-miR-96 transfection, relative to respective non-targeting controls, while a negative control target $\mathrm{CDH} 1$ was not affected (Fig. 7d). Intriguingly, the single transcript not downregulated in this experiment, p27 (encoded by $C D K N 1 B$ ), showed significantly reduced protein level upon miR-96 overexpression, suggesting that in some cases the result of miR- 

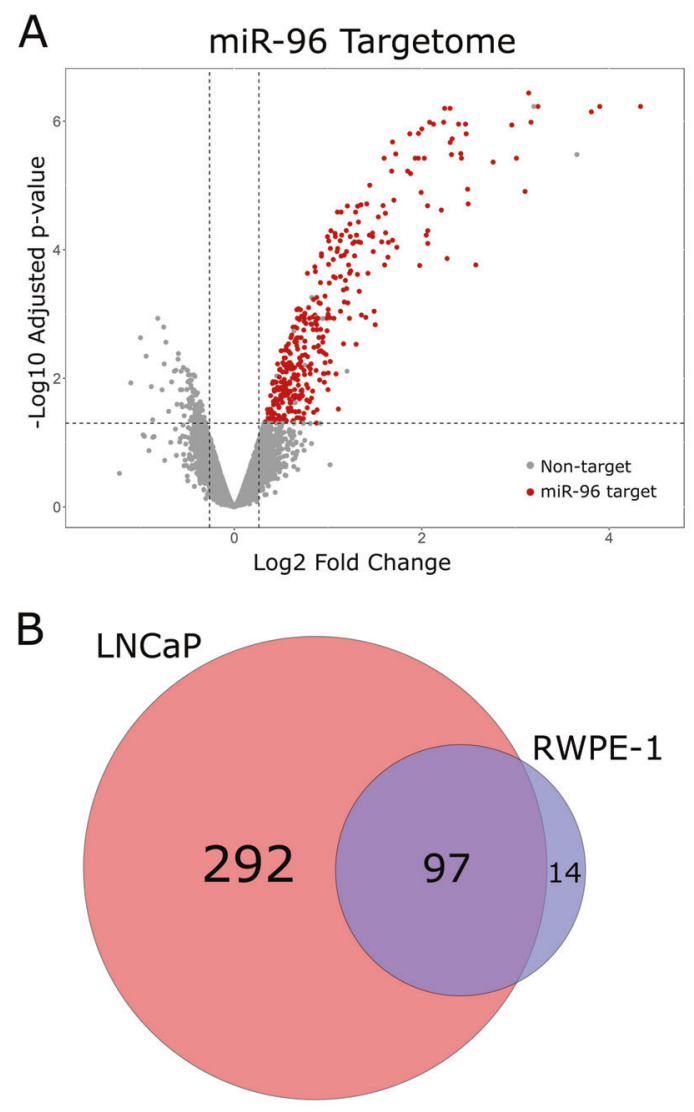

C
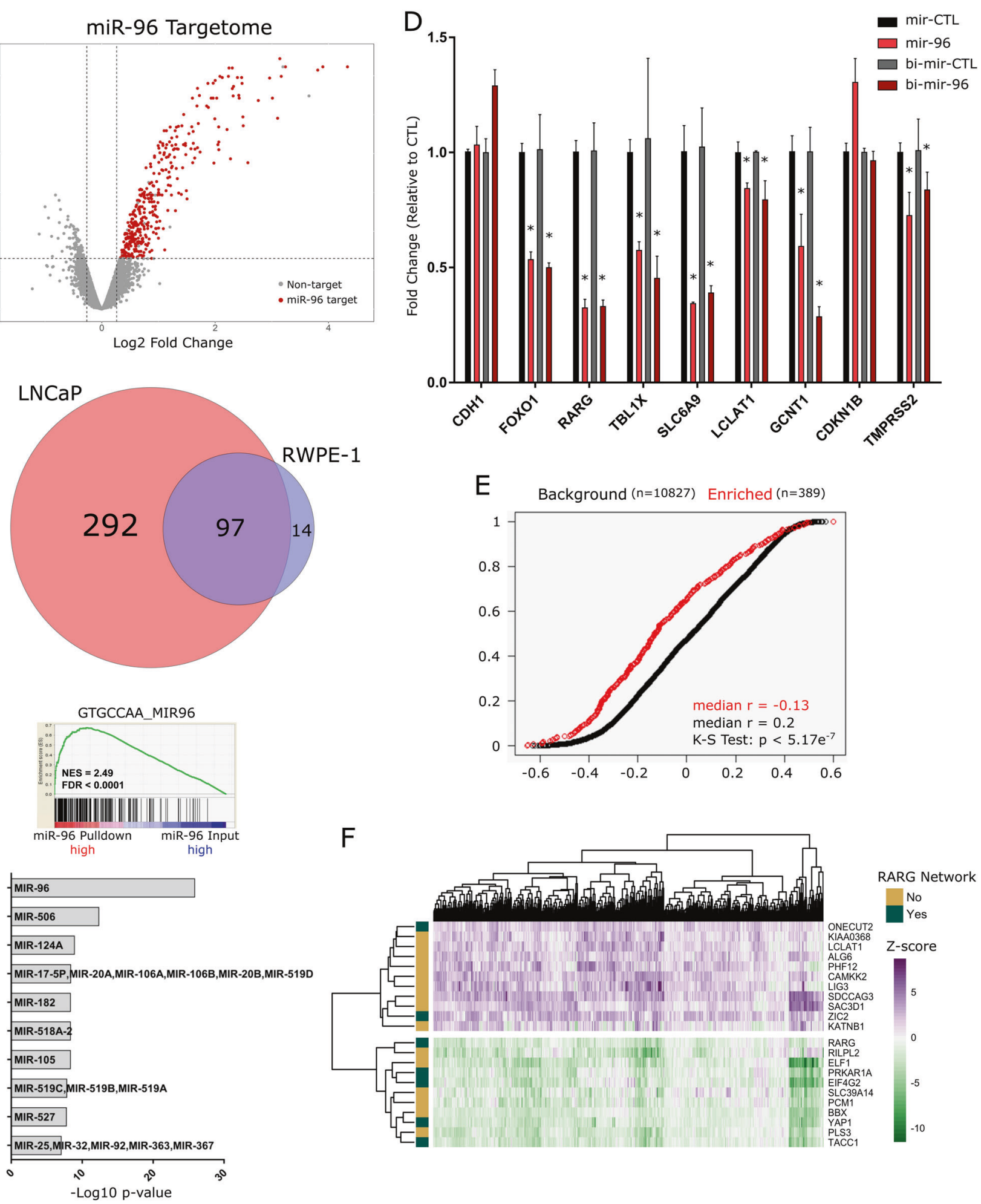

96 binding is translational inhibition and not degradation of transcript (Supplementary Figure 15G). Similar regulation of targets was observed in RWPE-1 cells (Supplementary Figure 15H).
Interestingly, in $\mathrm{LNCaP}$ cells $\mathrm{FOXO1}$ was also not significantly enriched in the bi-miR-96 fraction upon microarray analysis and was only validated by RT-qPCR in RWPE-1 cells. Also, RARG transcript was not significantly 
Fig. 7 The miR-96 targetome centers on a RAR $\gamma$ network. a LNCaP cells were transfected in triplicate with bi-miR-96 or bi-cel-miR-67 (non-targeting control, bi-miR-CTL) $(30 \mathrm{nM})$ for $24 \mathrm{~h}$ prior to cell lysis. Input (5\% of cell lysate) and streptavidin pulldown RNAs were isolated and analyzed by Illumina microarray (Illumina HT12v4) (DESeq2). Volcano plot depicting the enrichment of all genes in bimiR-96 pulldown over input in LNCaP cells. Genes marked in red $(n$ =389) were considered experimentally determined miR-96 direct targets, as they were significantly enriched $(\mathrm{FC}>1.2, p \cdot \operatorname{adj}<0.05)$ in bi-miR-96 pulldown but not in bi-miR-CTL pulldown. b Venn diagram representing the overlap of miR-96 targetomes in $\mathrm{LNCaP}$ and RWPE-1 cells. $\mathbf{c}$ The top significantly enriched GSEA pathway from unbiased enrichment analysis of bi-miR-96 samples in LNCaP cells (pulldown/input) (top), and summary of top miRNA seed sequence matches in $3^{\prime}$ UTR regions of experimentally determined miR-96 targets using the GSEA-MSigDB microRNA targets tool (bottom). d Either bi-miR-96 or non-biotinylated miR-96 mimics or respective control mimics were transfected $(30 \mathrm{nM})$ in $\mathrm{LNCaP}$ cells for $48 \mathrm{~h}$ and target gene expression examined in triplicate. $C D H 1$ was assessed as a negative control, and specific targets were chosen as they were either previously validated (FOXO1, RARG) and/or were significantly enriched in bi-miR-96 pulldown profiling. Significance of difference in target transcript level between biotinylated and non-biotinylated miR96 relative to respective controls is noted $(* p<0.05)$. e Cumulative distribution plot comparing the correlations (Pearson's $r$ ) between miR-96 and all detectable genes from bi-miR-pulldown assay $(n=$ 10,827 , black) in TCGA-PRAD cohort samples compared to the correlations between miR-96 and identified miR-96 targets $(n=389$, red) across the same samples. Significant difference between distributions is determined by Kolmogorov-Smirnov test. f Heatmap depicting expression of annotated miR-96 targetome genes in the TCGA-PRAD cohort (pheatmap). Genes were filtered to identify those genes that were altered by more than $\pm 2 \mathrm{Z}$ scores in $35 \%$ of tumors relative to normal samples. Functional relationship of identified miR96 target genes to the previously established $\operatorname{RAR} \gamma$ network are indicated

detectable via microarray in either LNCaP or RWPE-1 cells, but did validate by RT-qPCR in both cell types. It was revealed that the Illumina HT12v4 Bead Chip array contains only a single exon probe targeting a single $R A R G$ isoform. $R A R G$ expression in $\mathrm{LNCaP}$ cells has been reported suggesting that the microarray finding is a false negative one.

Functional annotation of the miR-96 targetome in LNCaP cells, based on Gene Ontology terms, revealed roles for miR-96 in governing cell cycle progression, metabolism, cell morphology and microtubule organization (Supplementary Figure 15A). These observations reflected the impact of miR-96 on cell cycle and included $C D K N 1 B$, $C D K 2, D I C E R 1$ and TACC1. Validation of the regulation of selected cell cycle regulators and transcription factors (e.g., $B T B D 3)$ was undertaken in LNCaP cells after transfection with miR-96 mimics. Expression of several of these (e.g. TACC1 and BTBD3) were suppressed (Supplementary Figure 15B, C).

To assess whether experimentally determined targets had expected relationships with miR-96 in clinical samples, the TCGA-PRAD data were examined again. In the first instance, we examined the correlation of expression between miR-96 and identified miR-96 targets. For example, there was a significant inverse correlation between miR96 and TACC1 in the TCGA-PRAD cohort $(r=-0.54)$ (Supplementary Figure 15D). Comparing the distribution of these correlations of derived miR-96 targets against that of the background transcriptome revealed a significant shift toward negative correlations between miR-96 and its targets, supporting a functional relationship $\left(p=5.17 \mathrm{e}^{-7}\right)$ (Fig. 7e).

Finally, we measured the distorted expression of the miR-96 targetome in the TCGA-PRAD cohort. Stringent filtering of expression of the miR-96 targetome genes $( \pm 2 Z$ scores in $35 \%$ of tumors relative to normal prostate tissue) identified 22 genes with significantly altered expression (Fig. 7f). Seven of these 22 genes included RARG itself as well as 6 other genes that are either established (TACC1 [35], ZIC2 [36], PRKAR1A [37], EIF4G2 [38]) or putative (ONECUT2 [39] and YAPl [40]) RAR co-regulators. Interestingly, the motif for ONECUT2 was enriched in the experimentally derived RAR $\gamma$ cistrome and has been previously identified as a miR-96 target [41].

\section{The miR-96 governed RAR $y$ network associates with recurrent prostate cancer}

Several lines of evidence support the concept that miR-96/ RAR $\gamma$ is a significant signaling axis in the prostate; in the absence of exogenous retinoid ligand, experimentally manipulating expression levels of $\operatorname{RAR} \gamma$ controls gene expression patterns and governs the sensitivity of the AR to DHT stimulation; miR-96 modulates the expression levels of RAR $\gamma$ and a number of interacting co-factors as well as RAR $\gamma$-associated regulatory functions; the expression of miR-96 and RAR $\gamma$ are reciprocal in murine and human tumors; both the gene targets of RAR $\gamma$ (e.g., CYP11Al) and miR-96 itself predict prostate cancer progression in patients.

To dissect the impact of the miR-96 regulation of RAR $\gamma$ further we examined how the correlations of each of the seven RAR $\gamma$ network genes were altered by expression levels of miR-96. Specifically, we identified the significant correlations between each of the seven RAR $\gamma$ network genes (EIF4G2, ONECUT2, PRKAR1A, RARG, TACC1, YAP1, ZIC2 [36]) alongside FOXAl with all RAR $\gamma$-dependent genes in the upper (miR-96 $6_{\text {high }}, n=123$ ) and lower (miR-96 $6_{\text {low }}, n=122$ ) quartile miR-96 expression TCGA-PRAD tumors. From these distributions we next calculated how the strength of each correlation changed between $\mathrm{miR}-96_{\text {high }}$ and miR-96 tumors. That is, we reasoned that correlations between RAR $\gamma$ network and RAR $\gamma$ target genes would significantly strengthen as miR-96 levels decreased. Testing these relationships revealed that this was true clearly for RARG and TACC1 (Fig. 8a). For example, the difference in the strength 
A

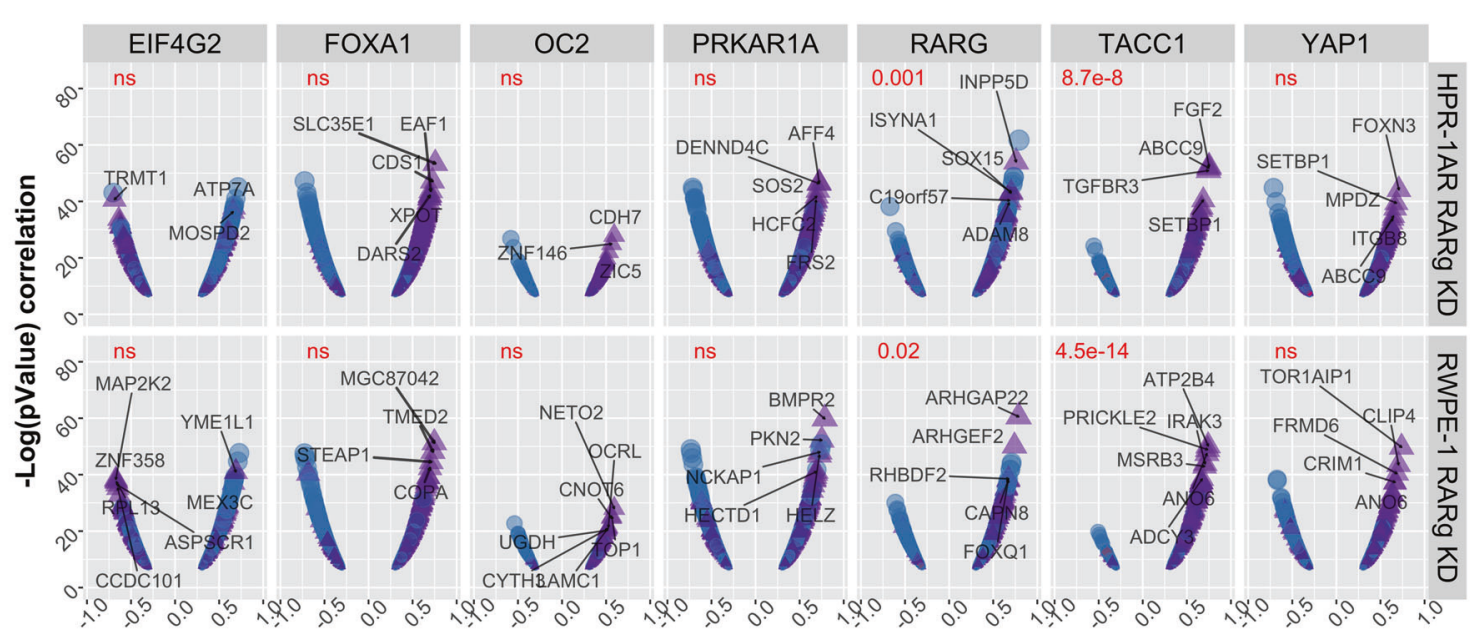

Estimate of correlation

Impact $\Delta$ Strengthen $>$ Switch $\bigcirc$ Weaken

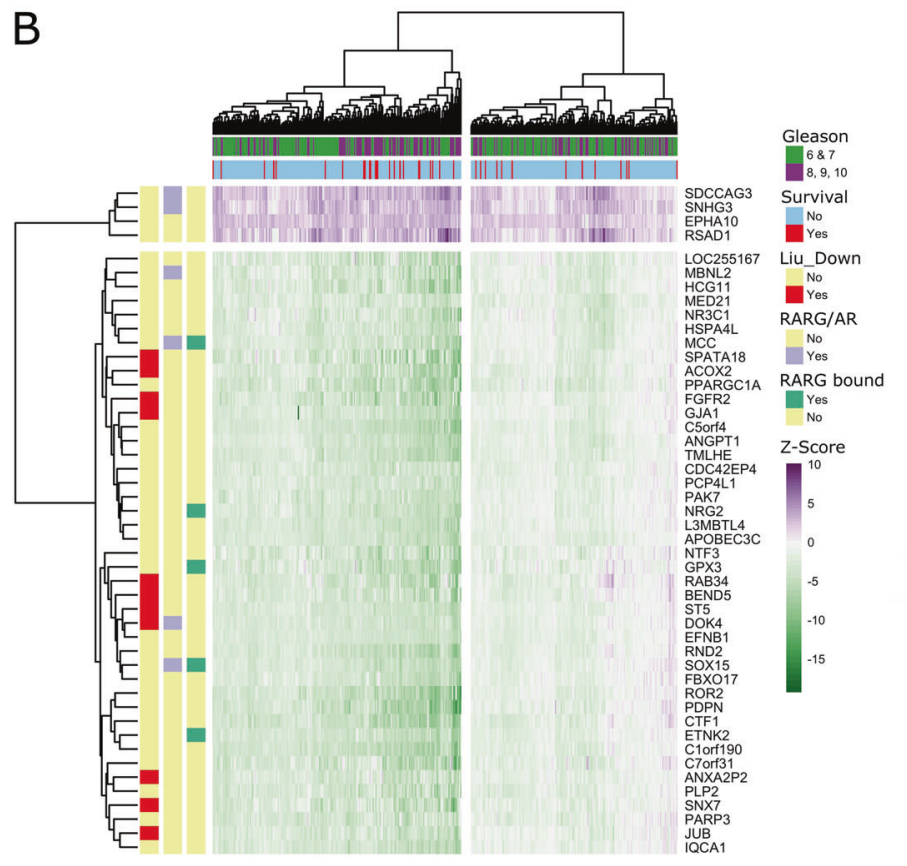

C

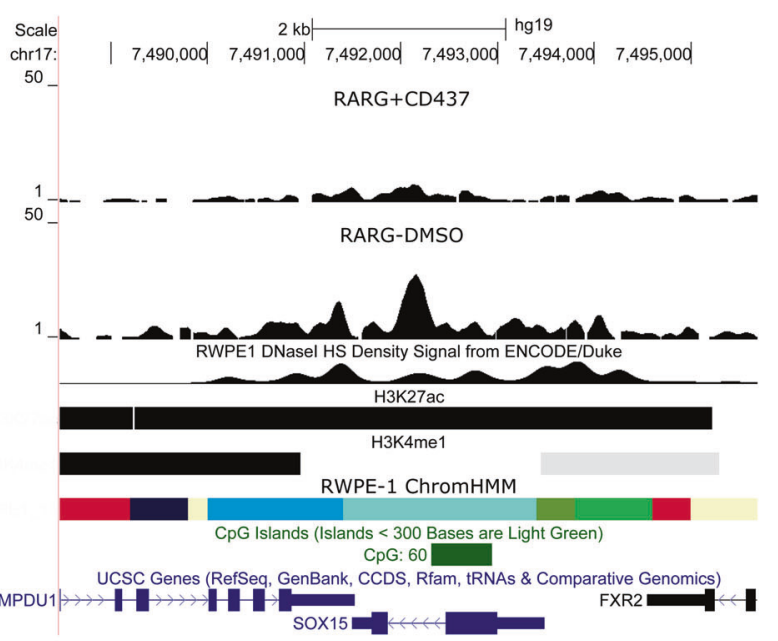

of the correlation between TACC1 and the genes altered by RAR $\gamma$ knockdown in HPr1-AR or RWPE-1 was measured between patients within the lower and upper quartile of miR96 levels (Welch two-sample $t$-test; $p \cdot \operatorname{adj}=8.7 \mathrm{e}^{-8}$ and $4.5 \mathrm{e}^{-14}$ with HPr1-AR or RWPE-1 knockdown genes, respectively).

Therefore, we sought to establish the combined significance of miR-96/RAR $\gamma /$ TACC1 axis in PCa by further segregating tumors in the TCGA-PRAD cohort into low quartile expression of RAR $\gamma$ and TACC1 (RAR $\gamma / \mathrm{TAC}-$ $\mathrm{Cl}_{\text {low }}$ ) and miR-96 $6_{\text {high }}$ expression. These were compared to the reciprocal (RAR $\gamma / \mathrm{TACCl}_{\text {high }}$, miR-96 low $)$ (Fig. 1) for DEG analysis. This approach identified 1728 genes, which were then overlapped with the gene sets developed throughout this study to establish how they related to the various conditional $\operatorname{RAR} \gamma$ networks identified. Using hypergeometric testing, we measured the significance of overlaps between the in vitro derived gene sets and those identified in the miR-96/RAR $\gamma /$ TACC1 axis in TCGAPRAD. For example, 118 genes were shared between RAR $\gamma$ knockdown in RWPE-1 and HPr1-AR overlapped ( $p=7.6 \mathrm{e}$ ${ }^{-12}$ ), and 119 genes were shared between miR-96/RAR $\gamma /$ TACC 1 axis genes RAR $\gamma$-dependent genes in HPr1-AR ( $p$ $=5.3 \mathrm{e}^{-12}$ ) (Supplementary Figure 16A). These findings suggest that the underlying biology of RAR $\gamma$ dissected in cell line models was detectable in human tumors. 
Fig. 8 A miR-96/RAR $\gamma / \mathrm{TACC} 1$ network associates with recurrent prostate cancer. a For each of the seven miR-96/RAR $\gamma$ networkassociated genes (EIF4G2, ONECUT2, PRKAR1A, RARG, TACC1, $Y A P 1, Z I C 2$ ) plus FOXA1 the Pearson's $r$ correlation was determined against all expressed genes within upper quartile of miR-96 expressing TCGA-PRAD tumors (miR-96 $\left.6_{\text {high }}, n=123\right)$ and separately within the lower quartile (miR-96 $\left.6_{\text {low }}, n=122\right)$. Significant correlations ( $q$-value $<0.1$ ) were selected for those genes that were RAR $\gamma$ dependent in either RWPE-1 (Fig. 3) or HPr1-AR (Fig. 5). The shift in the strength of the correlation between miR-96 $6_{\text {low }}$ compared to miR- $96_{\text {high }}$ tumors was calculated, the correlations in miR- $96_{\text {low }}$ tumors are visualized indicating if the correlation was strengthened, weakened or switched direction between miR-96 $6_{\text {low }}$ compared to miR-96 $6_{\text {high }}$. A $t$-test (Welch two-sample $t$-test) assessed the difference of the statistical strength of correlations between those that were positive and strengthened, compared to those correlations that were negative and weakened between miR-96 $6_{\text {low }}$ and miR-96 $6_{\text {high }}$ tumors. Genes that displayed the most significant change in correlation between miR-96 low and miR-96 $6_{\text {high }}$ tumors are indicated in each panel. There were fewer than 50 significant correlations with ZIC2 and is omitted. b TCGA-PRAD cohort tumor samples were separated based on expression of RAR $\gamma$, TACC1 and miR-96 (based on lower/upper quartile expression) to generate $\mathrm{RAR} \gamma / \mathrm{TACC} 1_{\text {low }}, \mathrm{miR}-96_{\text {high }}(n=60)$ and $\mathrm{RAR} \gamma / \mathrm{TACC} 1_{\text {high }}$, miR$96_{\text {low }}(n=66)$ tumors and differential expression undertaken. Filtering the 1728 differentially expressed genes between these tumors by $Z$ scores as described in Fig. $7 \mathrm{f}$ revealed which genes were most altered in the TCGA-PRAD cohort. Unsupervised hierarchical clustering of gene expression identified a group of tumors that after adjusting for age significantly associated with worse disease-free survival (hazard ratio 2.23 , 95\% CI 1.58 to $2.88, p=0.015$ ), and also clustered high Gleason score tumors $(p=0.012)$ (survival). Individual genes were annotated; RARG Bound are those identified by RAR $\gamma$ ChIP-Seq (Fig. 4); RARG/AR are those displaying RAR $\gamma$-dependent DHT regulation (Fig. 5); and enrichment in the Liu prostate cancer gene set (Liu_Down). c Representative image of the SOX15 locus, which is a RAR $\gamma$ dependent AR-regulated target, is bound by RAR $\gamma$ and also shows a significantly stronger correlation with $\mathrm{RAR} \gamma$ in miR-96 $6_{\text {low }}$ tumors relative to miR-96 $6_{\text {high }}$ tumors (a, upper panel). ChromHMM (cyan = TSS flanking; grass green $=$ low transcription; bright green $=$ active enhancer; red = transcriptional enhancer; blue=active TSS; pale yellow $=$ poised transcription), CpG island, histone (GSE63094) and DNase sensitivity (GSM1541008) tracks are also shown

We reasoned that if the genes identified as dependent upon the miR-96/RAR $\gamma / \mathrm{TACC} 1$ axis were critical in PCa, they would be commonly distorted and associate with aggressive disease. Filtering the $\sim 1700$ differentially expressed genes in RAR $\gamma / \mathrm{TACC} 1_{\text {low }}$, miR- $96_{\text {high }}$ tumors (altered by $\pm 2 Z$ scores in more than $45 \%$ of tumors relative to normal prostate tissue) revealed 47 genes. Unsupervised hierarchical clustering of the expression of these genes identified a group of patients in the TCGA-PRAD cohort that, after adjusting for age, significantly associated with high Gleason score tumors $(p=0.012)$ and worse diseasefree survival (hazard ratio 2.23, 95\% confidence interval (CI) 1.58 to $2.88, p=0.015$ ) (Fig. 8 b).

Genes were also annotated for whether they were identified as a RAR $\gamma$ cistrome gene (RARG bound); DHT-regulated RAR $\gamma$-dependent genes (RARG/AR); and member of the highest rank GSEA term (LIU_PROSTATE_CANCER_DN; a cohort of genes significantly downregulated in PCa [42]).
Five RAR $\gamma$ cistrome genes were revealed, all downregulated, including the tumor suppressor MCC [43] and other regulators of cell fate such as GPX3 and SOX15 [44] and MCC and SOX15 were also DHT-regulated RAR $\gamma$-dependent genes (Fig. 8c). Furthermore, the correlation between $R A R G$ and SOX15 was one of the top most strengthened correlations (Fig. 8a, upper panel). These findings support the concept that the miR-96/RAR $\gamma / \mathrm{TACC} 1$ axis can be detected in PCa cohorts, and contains genes that associated with AR crosstalk and the risk of disease recurrence.

\section{Discussion}

The rationale for the current study arose from our prior observation of the common downregulation, but neither the deletion nor mutation, of RAR $\gamma$ in PCa [7]. Therefore, we modulated $\mathrm{RAR} \gamma$ expression in three different prostate models to examine the consequences on cell viability and transcriptional responses. These data were complemented by RAR $\gamma$ ChIP-Seq data, and publicly available cistromic data sets to reveal that RAR $\gamma$ was significantly bound at gene enhancers and could significantly regulate the sensitivity of AR signaling. We next identified miR-96 targeting as a significant cause of downregulation of $\operatorname{RAR} \gamma$, and further revealed the miR-96 targetome to include a number of RAR $\gamma$ interacting co-factors. Finally, we revealed that tumors with upregulated miR-96 and downregulated RAR $\gamma$ were significantly more likely to recur following initial therapy.

Developmental roles for RAR $\gamma$ have been identified in skin, skeletal and reproductive systems, including the prostate [12]. Indeed, $\mathrm{Rarg}^{-1-}$ mice display prostate epithelial squamous metaplasia due to improper glandular formation [12]. More broadly, RAR $\gamma$ has emerged as an important transcription factor. For example, the Roadmap Epigenome consortium identified RAR $\gamma$ as a member of the most highly enriched in transcription factor-enhancer interactions across the human epigenome [45] and others have considered a role for the receptor to govern pluripotency [46]. RARG has also been suggested to be a tumor suppressor in keratinocytes [47].

We have now identified that the actions of RAR $\gamma$ are substantial in the absence of exogenous retinoid ligand, and potentially more biologically significant than the impact of retinoid exposure. Similar findings are also found in Rarg ${ }^{-1-}$ mice. Specifically, we analyzed publicly available microarray studies undertaken in $\mathrm{Rarg}^{-/-}$murine embryonic stem cells and also F9 cells [48]. This analysis, in a genetically clean system, revealed similar patterns resulting from depletion of RAR $\gamma$, namely deletion of receptor had the largest impact on gene expression, compared to treating wild-type cells with exogenous retinoid (Supplementary Figure 16B). 
There is a significant pre-clinical literature dissecting RARs in solid tumors including PCa [10, 49] with the goal of developing so-called differentiation therapies [50]. The goal of these approaches was to exploit retinoid signaling in $\mathrm{PCa}$ as a therapeutic approach to temper and subdue AR signaling. The frequently observed $\mathrm{CpG}$ methylation of the RAR $\beta$ perhaps underscores the significance of these receptors in PCa progression [51]. However, the phase I/II clinical trials of retinoids alone [52] or in combination [53] in patients with advanced PCa met with only limited clinical success [54, 55]. Furthermore, there are ambiguous relationships between serum levels of retinoid metabolites and PCa [56-58]. Nonetheless, there appears to be a significant biological relationship between RAR $\gamma$ and PCa [17].

Given that expression of RAR $\gamma$ regulated genes such as SOX15 associated with worse disease outcome, we propose that the reduction in $\mathrm{RAR} \gamma$ is clinically significant because it impacts the RAR $\gamma$ gene-regulation capacity in the absence of exogenous retinoid. These findings are also perhaps compatible with other receptors such as RAR $\beta$ being more prominent in the sensing of exogenous ligand in PCa cells [10].

A key finding from the current study is the role for RAR $\gamma$ regulation of AR signaling in PCa. Others have implicated RARs generally with PCa genomic states [59], or dissected RAR $\gamma$ crosstalk with AR signaling at the candidate gene level [17]. The current study therefore extends these earlier findings to develop a genomic understanding of the cellular and clinical significance of the role of RAR $\gamma$ in the absence of exogenous retinoid ligand. These findings also reflect an emerging understanding of the RAR $\gamma$ functional crosstalk with steroid receptor signaling in breast cancer [14].

Genomic RAR $\gamma$ binding in RWPE-1 cells, in the absence of exogenous ligand, significantly overlapped with histone modifications that defined active enhancers and DNase sensitivity (also in RWPE-1) and AR binding and p65 binding (in LNCaP). However, RAR $\gamma$ binding did not overlap with VDR binding in LNCaP. TCGA investigators [60, 61] and others [62] have identified common translocations between TMPRRS2 and ETS oncogenes in PCa [63, 64]. TMPRSS2 is androgen responsive, and its translocation leads to androgen regulation of ETS oncogenes, which in turn act as cancer drivers $[65,66]$. VCaP is a TMPRSS2 fusion-positive cell and therefore we examined how RAR $\gamma$ overlapped with AR and the ETS family member, ERG, in these cells. Interestingly, while RAR $\gamma$ overlapped with AR in LNCaP cells, it did not overlap with either AR or ERG in VCaP cells, and may reflect the impact of ERG on the genome.

RAR $\gamma$ loss profoundly altered AR-regulated events including DHT-mediated anti-proliferative effects [25] and reduced the sensitivity of the DHT-dependent transcriptome, notably by restricting the capacity of AR to repress MYC signaling. Recently, MYC has been shown to antagonize AR function in prostate cells [67], and the current study suggest that $\mathrm{RAR} \gamma$ regulates these events, in part through direct binding at the MYC locus.

It is possible that the changing expression levels of RAR $\gamma$ impacts the expression of co-factors that can be shared with the AR. To address this possibility we generated a comprehensive list of $\sim 1900$ transcription factor coregulators by mining FANTOM, Uniprot and the HGNO databases and tested how these overlapped with the gene expression following RAR $\gamma$ knockdown in each of RWPE1, HPr1-AR and LNCaP (Supplementary Figure 17). This approach identified co-activators appeared to be commonly enriched in gene sets that resulted from changes to RAR $\gamma$ (e.g., knockdown of RAR $\gamma$ in RWPE-1, $n=47$ ), and DEGs associated with the miR-96/RAR $\gamma / \mathrm{TACC} 1$ axis in TCGAPRAD tumors $(n=49)$. This leads to the intriguing suggestion that $\operatorname{RAR} \gamma$ levels regulate expression of a number of co-regulators, which in turn impact how the AR signals. These co-regulators included FHL2 [68], a co-regulator of FOXO1; LPIN1 [69] and PPARGC1B [70], which interact with PPARs signaling; several negative co-regulators of WNT (DKK1, DKK3, PRICKLE1, SFRP1) [71] and HIPPO (WWTRl) [72] signaling. However, in the context of the current study, the number of genes prohibits obvious intervention approaches (e.g., overexpression or knockdown).

Although miR-34c targets $R A R G$ in embryonic stem cells [73], we found no significant relationship between miR-34c and RAR $\gamma$ in the current study. Rather, we identified miR96, which has been investigated in various cancer settings including in PCa, but not associated with RAR $\gamma[31,74]$. Furthermore, miR-96 is one of the 60 miRNAs whose expression most differentiated $\mathrm{PCa}$ clinical groups in TCGA-PRAD cohort [9].The current study extends these reports of oncogenic actions of miR-96 to identify the RAR $\gamma$ network as a major biological and clinically relevant target.

The inverse relationships between miR-96 and RAR $\gamma$ were robust and significant across cell models, murine $\mathrm{PCa}$ models and clinical cohorts, and equal or greater than with previously identified targets including FOXO1. Biochemical tests established that miR-96 binds directly to multiple target sites contained within the 3'UTR of $R A R G$, and using the bi-miR capture approach revealed $\sim 400$ direct targets enriched for predicted miR-96 target sequences, and identified targets were directly bound and downregulated upon miR-96 overexpression.

Experimental overexpression of miR-96 positively regulated proliferation and cell cycle in $\mathrm{PCa}$ cells reflecting previous reports [31], but did not affect proliferation in nonmalignant prostate cells. It is thus interesting to speculate that miR-96 acquires additional targets and subsequent 
functions within the malignant transcriptome, which coincides with the observation of threefold additional targets in malignant LNCaP cells relative to non-malignant RWPE-1, and impacts the control of cell cycle progression. Given that RAR $\gamma$ appears to function as an important AR co-regulator to promote differentiation, then its downregulation by miR96 targeting suggests an oncogenic action that shifts the AR signaling capacity in localized PCa. Notably, miR-96 has previously been reported as androgen regulated in prostate cells [75]. Filtering miR-96 target genes to those most altered in PCa revealed that nearly one third (7/22) were within an RAR $\gamma$-centric network of co-regulators, suggesting its regulation as an important aspect of miR-96 function.

Differential expression analyses in TCGA-PRAD cohort between tumors showing reciprocal expression of miR-96 and RAR $\gamma / \mathrm{TACC} 1$ clustered aggressive tumors and predicted worse disease-free patient survival (Fig. 8b). That is, within the TCGA-PRAD cohort, 390 out of 498 tumors have data on disease-free survival and Gleason score, and of these, 37 have recurrent disease. The differential expression of these genes determined by RAR $\gamma / \mathrm{TACC} 1$ and miR-96 expression significantly predicts the risk of developing recurrent disease. We suggest therefore that this gene panel may be of interest to test in larger clinical cohorts or as part of meta-analyses.

Interestingly, recently $\mathrm{TACC} 1$ and $\mathrm{RAR} \gamma$ interactions have been identified to be critical for neural development [76]. Several of the shared target genes identified in the current study are either underexplored in PCa (e.g., SOX15 and $M C C)$ or have only been investigated in metastatic $\mathrm{PCa}$ [77] (PPARGC1A). Together, these data strongly support the concept that the miR-96/RAR $\gamma$ is a significant and yet underexplored regulator of the $\mathrm{AR}$ and drives $\mathrm{PCa}$ progression.

Finally, we believe these studies may form a platform for a number of highly translational follow on studies. That this AR-centered transcriptional circuit is regulated by miR-96 adds diagnostic and therapeutic potential. In the first instance, miR-96 may have significant diagnostic potential when measured in the tumor or serum of new PCa patients [78-81], and have potential to be targeted with antagomiRbased therapies [82, 83].

We also believe it is timely to revisit the previous clinical experience with targeting retinoid signaling in $\mathrm{PCa}$. We propose that a lack of success in clinical exploitation of retinoid-based therapies in $\mathrm{PCa}$ reflects an underappreciation of the role of $\operatorname{RAR} \gamma$ to function in the absence of exogenous ligand. These functions are centered on the regulation of gene networks that relate to the regulation of AR function and broader impact on cell proliferation and differentiation. It is reasonable to propose that there may also exist under-appreciated genomic functions for other type II nuclear receptors (e.g., VDR, PPARs, FXR,
LXRs, CAR) [84-86] that exert genomic functions in the absence of exogenous ligand and are potential targets in cancer.

\section{Materials and methods}

\section{Data analyses, integration and code availability}

All analyses were undertaken using the $\mathrm{R}$ platform for statistical computing (version 3.1.0) and a range of library packages were implemented in Bioconductor [87]. All codes are available upon request from the corresponding author. All data is publicly available through GEO (Series GSE117182).

\section{Cell culture and materials}

All cells were maintained at $37^{\circ} \mathrm{C}$ and $5.0 \% \mathrm{CO}_{2}$ using a cell culture incubator with UV contamination control (Sanyo). RWPE-1, RWPE-2, PNT2 and HPr1-AR cells were maintained in Keratinocyte-Serum Free Medium containing human recombinant epidermal growth factor 153 and bovine pituitary extract. LNCaP, LAPC4, EAA006, MDAPCa2b, LNCaP-C42, 22Rv1, PC3 and DU145 cells were maintained in RPMI-1640 medium containing $10 \%$ fetal bovine serum. All media were supplemented with 100 $\mathrm{U} / \mathrm{mL}$ penicillin-streptomycin. ATRA, CD437 and DHT (sigma) were kept in dimethyl sulfoxide (DMSO) or ethanol $(\mathrm{EtOH})$ stocks, and diluted to $1000 \times$ stocks in DMSO prior to treatments. All cells were sourced from ATCC.

\section{Stable knockdown of RARy}

Knockdown of RAR $\gamma$ in RWPE-1, LNCaP and HPr1-AR cells was achieved by stable selection after transduction with lentiviral shRNA constructs targeting RARG. Two targeting constructs (V2LHS_239272, V2LHS_239268) and one non-silencing control construct were selected from the V2LHS pGIPZ-based lentiviral shRNA library (Thermo Fisher Scientific) for testing. Viral packaging and cellular infection was performed through the RPCCC shRNA Resource. All pGIPZ-containing cells were subsequently maintained in media supplemented with puromycin $(2 \mu \mathrm{g} /$ $\mathrm{mL}$ ), including during all experiments.

\section{BAC-RARG-EGFP}

BAC-RARG-EGFP construct (CTD-2644H7) was a generous gift of Dr. Kevin White (University of Chicago). RWPE-1 cells were transfected with BAC-RARG-EGFP construct using Lipofectamine ${ }^{\circledR} 3000$ and selected with G418 and consistently maintained under antibiotic selection 
for all subsequent passaging of cells and also during experiments.

\section{Cell viability}

Bioluminescent detection of cellular adenosine triphosphate (ATP) as a measure of cell viability was undertaken using ViaLight ${ }^{\circledR}$ Plus Kit (Lonza Inc.) reagents. Cells were plated at optimal seeding density to ensure exponential growth $\left(4 \times 10^{3}\right.$ cells per well) in 96-well, white-walled plates. Wells were dosed with agents to a final volume of $100 \mu \mathrm{L}$. Dosing occurred at the beginning of the experiment, and cells were incubated for up to $120 \mathrm{~h}$. Luminescence was detected with Synergy $^{\mathrm{TM}} 2$ multi-mode microplate reader (BioTek ${ }^{\circledR}$ Instruments). Each experiment was performed in at least triplicate wells in triplicate experiments.

\section{Cell cycle analysis}

Cells were seeded in $100 \times 20 \mathrm{~mm}$ sterile, polystyrene tissue culture dishes (Corning Inc.) at densities previously optimized for each cell line, and were allowed exponential growth with our without ligand for specified times (RWPE1: $1 \mu \mathrm{M}$ ATRA or $10 \mathrm{nM} \mathrm{CD} 437$ for $72 \mathrm{~h}$ with re-dosing after $48 \mathrm{~h}$, LNCaP: $1 \mu \mathrm{M}$ ATRA or $250 \mathrm{nM}$ CD437 for 120 $\mathrm{h}$ with re-dosing after 48 and $96 \mathrm{~h}$ ). Mid-exponential growth cell cultures were harvested with accutase (Invitrogen), fixed and stained with propidium iodide buffer $(10 \mu \mathrm{g} / \mathrm{mL}$ propidium iodide, $1 \%$ (wt/vol) trisodium citrate, $0.1 \%$ (vol/ vol) Triton $\mathrm{X}-100,100 \mu \mathrm{M}$ sodium chloride) for $1 \mathrm{~h}$, on ice, in the dark. Cell cycle distribution was determined utilizing FACSCalibur $^{\mathrm{TM}}$ Flow Cytometer (Becton-Dickinson) and analyzed with ModFIT 3.1 SP3 cell cycle analysis software.

\section{RT-qPCR}

RT-qPCR was employed for detection of target mRNA transcripts. Total RNA was isolated via TRIzol ${ }^{\circledR}$ reagent (Thermo Fisher Scientific) for candidate detection or by use of the High Pure RNA Isolation Kit (Roche), following the manufacturer's protocols. Complementary DNA (cDNA) was prepared using iScript ${ }^{\mathrm{TM}}$ cDNA Synthesis Kit (Bio-Rad) according to the manufacturer's protocol. Relative gene expression was subsequently quantified via Applied Biosystems 7300 Real-Time PCR System (Applied Biosystems) for both TaqMan and SYBR Green (Thermo Fisher Scientific) applications. All targets were detected using either predesigned TaqMan Gene Expression Assays (Thermo Fisher Scientific; $A L D H 1 A 2, A R, C D H 1, C D K N 1 B, C R A B P 1$, FOXO1, GAPDH, GCNT1, Gusb, KRT8, LCLAT1, PPARG, RARA, RARB, RARG, Rarg, SLC6A9, TBL1X, TGM4, TP63), pre-designed PrimeTime qPCR primers (IDT; BTBD3, CYP26A1, EIF4G2, ELF1, KRT10, KRT18, LRAT,
MORF4L1, PAFAH1B1, PRKARIA, SMAD4, TACC1, USP9X, ZNF430) or custom designed qPCR primers (IDT) using a final primer concentration of $500 \mathrm{nM}$. All primers for use with SYBR Green application were tested for specificity by melting curve analysis with subsequent product visualization on agarose gel. All RT-qPCR experiments were performed in biological triplicate, with at least technical duplicate. Fold changes were determined using the $2^{-\Delta \Delta C t}$ method, where $\Delta \mathrm{Ct}$ was calculated as the $\mathrm{Ct}$ of the target gene minus the $\mathrm{Ct}$ of endogenous control, and $\Delta \Delta \mathrm{Ct}$ was calculated as the difference between experimental group and respective control group. Significance of experimental comparisons was performed using Student's $t$-test.

\section{Immunoblotting}

Total cellular protein was isolated from exponentially growing cells for determination of target protein expression. Cells were harvested, then washed in ice-cold phosphate-buffered saline (PBS) before lysing in ice-cold RIPA buffer $(50 \mathrm{mM}$ Tris-HCl pH 7.4, $150 \mathrm{mM} \mathrm{NaCl}, 1 \%$ v/v Triton X-100, $1 \mathrm{mM}$ EDTA $\mathrm{pH} 8.0,0.5 \% \mathrm{w} / \mathrm{v}$ sodium deoxychlorate, $0.1 \% \mathrm{w} / \mathrm{v}$ SDS) containing $1 \times$ cOmplete Mini Protease Inhibitor Tablets (Roche). Protein concentrations were quantified using the DC Protein Assay (Bio-Rad) as per the manufacturer's instructions. Equal amounts of proteins $(30-60 \mu \mathrm{g})$ were separated via SDS-polyacrylamide gel electrophoresis using precast $10 \%$ polyacrylamide gels (Mini-Protean TGX, Bio-Rad). Proteins were transferred onto polyvinylidene fluoride membrane (Roche) for $80 \mathrm{~V}$ for $1.5 \mathrm{~h}$. Post transfer, membranes were blocked with $5 \%$ non-fat dry milk for $1 \mathrm{~h}$ at room temperature. Blocked membranes were probed with primary antibody against RAR $\gamma$ (sc550, Santa Cruz), GFP (ab290, Abcam), p27 (D37H1, Cell Signaling) or GAPDH (2118 s, Cell Signaling) either overnight at $4{ }^{\circ} \mathrm{C}$ or for $3 \mathrm{~h}$ at room temperature. Primary antibody was detected after probing for $1 \mathrm{~h}$ with horseradish peroxidase-linked rabbit anti-mouse IgG (P0161, Dako) or goat anti-rabbit IgG (P0448, Dako) secondary antibody at room temperature using ECL Western Blotting substrate (Pierce). Signal and quantification was performed using the ChemiDoc XRS + system (Bio-Rad).

\section{Expression determination in PCa mouse models}

Snap frozen tissue and/or RNA from previously harvested normal or malignant prostate tissues of Hi-MYC, PTEN $-/-$ and TRAMP (5 tumors at each of $6,8,10,15$ and 20 25 weeks) models, as well as from age-matched wild-type (10 prostates from FVB:BL6, C57BL/6) mice, was obtained from the lab of Dr. Barbara Foster at RPCCC. Relative expression of Rarg and microRNAs was determined in these tissues by RT-qPCR after normalization to Gusb or RNU6B, respectively. 


\section{miRNA mimic, antagomiR and siRNA transfection}

Ectopic overexpression of miRNA was achieved by transient transfection of mirVana ${ }^{\circledR}$ miRNA mimics $(30 \mathrm{nM})$ (Ambion). Inhibition of miRNA was achieved by transient transfection of Anti-miR ${ }^{\mathrm{TM}}$ miRNA Inhibitor $(30 \mathrm{nM})$ (Ambion). For transient silencing of targets, siRNA was employed using Silencer ${ }^{\circledR}$ predesigned siRNAs $(30 \mathrm{nM})$ (Ambion). Transfection was accomplished using Lipofectamine $^{\circledR} 2000$ or Lipofectamine ${ }^{\circledR} 3000$ following the manufacturer's instructions. Concentrations of miRNA mimics and transfection reagents were optimized using BLOCK-iT ${ }^{\mathrm{TM}}$ Alexa Fluor ${ }^{\circledR}$ Red Fluorescent Control (Ambion) as well as by subsequent miRNA-specific RTqPCR (TaqMan MicroRNA Reverse Transcription Kit, Thermo Fisher Scientific) and RT-qPCR of target mRNAs to assess efficiency of transfections.

\section{RPCCC and TCGA PCa samples}

RNA was obtained from a cohort of 36 men who underwent radical prostatectomy at RPCCC and de-identified tissue made available through the Pathology Resource Network (PRN) and Data Bank and BioRepository (DBBR) [88] shared resources at RPCCC. Areas of histologically normal tissue and areas with high percentages of neoplastic tissue were isolated and RNA extracted. De-identified patient codes were matched with Gleason scores for each sample, were made available through the RPCCC Clinical Data Network (CDN).

PCa data sets were downloaded through cBioPortal. The MSKCC dataset $(n=109)$ was in a tumor-normal $Z$ score format and the TCGA-PRAD cohort $(n=498 ; 390$ with progression data) was also converted to this format. Expression of overlapping genes were filtered (genefilter) as indicated before visualization and clustering of expression (pheatmap) and testing the relationship between expression and patient outcomes (survival).

\section{Molecular cloning/luciferase assay}

Luciferase assay was employed to assess direct targeting of miR-96 to the full-length (FL) RARG 3'UTR or individual predicted target sites ( 1 1, t2) within the RARG 3'UTR. RSV-pGL3-basic firefly luciferase expressing vector (Addgene) was employed for this purpose, utilizing FseI and $X b a \mathrm{I}$ restriction sites located between the $l u c+$ gene and the SV40 pA tail. Primer sets were designed for PCR amplification of either the $\sim 1100$ bp FL RARG $3^{\prime}$ UTR or two smaller regions $(\sim 300 \mathrm{bp})$ within the $R A R G 3^{\prime} \mathrm{UTR}$ containing individual predicted miR-96 target sites $(\mathrm{t} 1, \mathrm{t} 2)$. PCR amplicons were digested and ligated to RSV-pGL3basic vector via T4 DNA Ligase in $1 \mathrm{X}$ T4 DNA Ligase
Buffer (New England BioLabs, Inc.), using an insert to vector ratio of 2.6. Individual transformed Escherichia coli colonies were expanded prior to plasmid isolation via E.Z. N.A ${ }^{\circledast}$ Plasmid Mini Kit (Omega), and inserts verified by Sanger sequencing. RWPE-1 cells were seeded in 96-well plates and then co-transfected with combinations of miR-96 or miR-control mimics $(30 \mathrm{nM})$, indicated RSV-pGL3 constructs $(250 \mathrm{ng})$ and pRL-CMV Renilla luciferase expressing vectors $(25 \mathrm{ng})$ via Lipofectamine ${ }^{\circledR} 2000$ for 48 h. Media were subsequently removed, cells washed with PBS and both firefly and Renilla luciferase activity measured by Dual-Glo Luciferase Assay System (Promega). For each construct (FL, t1, t2, empty), detected firefly luminescence was first normalized to Renilla luminescence, and then normalized luminescence was compared between miR96 and miR-control transfected cells. Experiments were performed in technical triplicate, and experiment replicated a total of 5 times.

\section{Chromatin immunoprecipitation}

ChIP was performed in BAC-RARG-EGFP containing RWPE-1 cells in the presence of CD437 $(10 \mathrm{nM}, 2 \mathrm{~h})$ or DMSO as previously described [6]. Briefly, triplicate cultures of approximately $20 \times 10^{6}$ cells were crosslinked with $1 \%$ formaldehyde solution, quenched with glycine $(0.125$ $\mathrm{M})$ and harvested in cold PBS. Sonication of crosslinked chromatin was performed using a Bioruptor ${ }^{\circledR}$ UCD-200 TM Sonicator (Diagenode) for a total of $15 \mathrm{~min}$. Immunoprecipitation of sonicated material was performed with antibodies against enhanced green fluorescent protein (ab290, Abcam) or IgG (sc-2027×, Santa Cruz) for $16 \mathrm{~h}$, and antibody/bead complexes isolated with Magna $\mathrm{ChIP}^{\mathrm{TM}}$ Protein $\mathrm{A}+\mathrm{G}$ magnetic beads (Millipore). Complexes were washed, reverse crosslinked and treated sequentially with RNase and proteinase $\mathrm{K}$ prior to DNA isolation. Sequencing (100 bp single end, $>30 \times 10^{6}$ average reads/sample) was performed at the RPCCC Genomics Shared Resource core facility. The RAR $\gamma$ cistrome was analyzed with Rsubread/csaw [89], along with TF motif analyses (MotifDb). Binding site overlaps between RAR $\gamma$ and the other cistromes were tested (ChIPpeakAnno [90] and bedtools). Peak density plots were performed using the annotatePeaks.pl tool available from the HOMER (Hypergeometric Optimization of Motif EnRichment) suite.

\section{Biotin-miRNA pulldown}

Approximately $20 \times 10^{6}$ were transfected with either hsamiR-96-5p or cel-miR-67 miRIDIAN miRNA mimics (30 $\mathrm{nM}, 24 \mathrm{~h}$ ) modified with a 3 'biotin attached to the guide strand (Thermo Fisher Scientific) using Lipofectamine 3000 Transfection Reagent (Invitrogen). Harvested cell pellets 
were resuspended in cell lysis buffer $(10 \mathrm{mM} \mathrm{KCl}, 1.5 \mathrm{mM}$ $\mathrm{MgCl}_{2}, 10 \mathrm{mM}$ Tris-Cl pH 7.5, $5 \mathrm{mM}$ DTT, 0.5\% IGEPAL CA-630) containing SUPERase.In (Ambion) and $1 \times \mathrm{cOm}-$ plete Mini protease inhibitor (Roche) and cleared by centrifugation. Then, $5 \%$ of cell lysate was collected to serve as lysate RNA input. Dynabeads MyOne ${ }^{\mathrm{TM}}$ Streptavidin C1 (Thermo Fisher Scientific) were washed 3 times with bead wash buffer (5 mM Tris-Cl pH 7.5, 0.5 mM EDTA, $1 \mathrm{M}$ $\mathrm{NaCl})$, and then blocked $(1 \mu \mathrm{g} / \mu \mathrm{L}$ bovine serum albumin, 1 $\mu \mathrm{g} / \mu \mathrm{L}$ Yeast tRNA, $50 \mathrm{U} / \mathrm{mL}$ RNaseOUT) for $2 \mathrm{~h}$. Resuspended beads were added 1:1 to cell lysate, and mixed for $30 \mathrm{~min}$. Bead-lysate mixtures were collected with a magnetic rack, and bead-bi-miR complexes washed a total of 3 times with wash buffer. Bead-bi-miR complexes and input control samples were resuspended in water and purified using the Qiagen RNeasy ${ }^{\circledR}$ Mini kit (Qiagen) according to the manufacturer's RNA clean-up protocol. To concentrate samples for downstream analyses, eluted RNA was brought up to a total volume of $500 \mu \mathrm{L}$ in $\mathrm{H}_{2} \mathrm{O}$ and filtered through Amicon Ultra- $0.5 \mathrm{~mL}$ Centrifugal Filters (EMD Millipore) according to the manufacturer's instructions. Subsequent amplification and labeling of $50 \mathrm{ng}$ of pulldown and input RNA was performed at the RPCCC Genomics Core Facility, using the Illumina ${ }^{\circledR}$ TotalPrep RNA Amplification kit, including $14 \mathrm{~h}$ of incubation for the IVT step. Hybridization of cRNA samples onto Illumina Human HT12v4 bead arrays and successive scanning and raw intensity measurement extraction were also performed at the RPCCC Genomics Core Facility.

\section{miRNA analyses}

To reveal putative NR-targeting miRNA, miRWalk, a comprehensive database on predicted and validate miRNA targets, was employed. If at least 5 out of 9 algorithms positively predicted an interaction, it was considered in subsequent analyses. MiRNA expression was queried in PCa tissue samples and matched normal tissue from TCGA cohort data as previously described [7]. To examine if NRtargeting miRNA expression alterations significantly deviated from what would be expected by chance, bootstrapping approaches were utilized as previously described [7].

\section{Microarray/RNA-seq analyses}

Global changes in mRNA, biological triplicate samples per experimental condition were analyzed using Illumina microarray (Illumina HT12v4) or by RNA-seq (limma [91] or DESeq2 [92]). For RNA-seq data, raw sequence reads (75 bp paired end, $>45 \times 10^{6}$ average reads/sample) were aligned to the human genome (hg19) using tophat2, and aligned reads translated to expression counts via featureCounts, followed by a standard DESeq2 pipeline.

\section{Functional annotation gene sets}

Functional annotations were performed using GSEA v3.0 and gene sets from the Molecular signatures database (MSigDB). Specifically, gene sets were compiled to assess enrichment of all BROAD Hallmark pathways, curated pathways (KEGG, BioCarta, Canonical, Reactome, Chemical/Genetic perturbations) and transcription factor motif gene sets. Additionally, several candidate gene sets were included from previous studies, including microarray analyses of HPr1-AR cells treated with DHT [93], compiled gene sets previously utilized to encompass androgen response in PCa patients [9] as well as gene sets differentiating basal from luminal prostate epithelial cells [94]. In total, 4204 gene sets were queried.

To identify meta-groups within enriched (NES $>1.8$, FDR $q$-value $<0.05$ ) gene sets, keywords from gene set identifiers were compiled, and frequency tables determined for all keywords across all gene sets and within enriched gene sets. To account for background frequencies of given terms across gene sets, hypergeometric testing was used to determine if the frequency of key words within enriched gene sets was greater than expected.

\section{Validation of miR-96 target sites and functional annotation}

Unbiased assessment of miRNA seed sequence binding motifs in experimentally determined miR-96 target transcript 3'UTR regions was performed using the MSigDB microRNA targets collection and topGO package implemented in R. Significantly enriched terms $($ FDR $<0.05)$ by both methods were simultaneously visualized using Cytoscape 3.2.0.

Author contributions MDL, PRvdB and MJC all participated in the integrative analyses of RAR $\gamma$ functions. MDL generated and characterized the RAR $\gamma$ knockdown cells and all genomic data sets. MDL, DJS, LES-C, PKS and MJC participated in study design and implementation. MJC conceived of the study, and participated in its design and coordination and directed the drafting of the manuscript. All authors read and approved the final manuscript.

Funding LES-C acknowledges support, in part, of Roswell Park Comprehensive Cancer Center-University of Pittsburgh Cancer Institute Ovarian Cancer Specialized Program of Research Excellence National Institutes of Health [P50CA159981-01A1]. MDL acknowledges support of Molecular Pharmacology and Experimental Therapeutics NRSA T32 program (T32CA009072) held at Roswell Park Comprehensive Cancer Center. MJC and DJS acknowledge support in part from the Prostate program of the Department of Defense Congressionally Directed Medical Research Programs (W81XWH-14-10608, W81XWH-11-2-0033) and the National Cancer Institute (NCI) grant P30CA016056 involving the use of Roswell Park Comprehensive Cancer Center's Genomic Shared Resource. MJC, GL, AR, and PRvdB acknowledge support from the European Union-United States Atlantis Program (P116J090011). MJC and LES-C acknowledge 
support from the National Cancer Institute (NCI) grant P30CA016056 involving the use of OSUCCC The James, CCSG P30CA016058.

\section{Compliance with ethical standards}

Conflict of interest The authors declare that they have no conflict of interest.

Open Access This article is licensed under a Creative Commons Attribution 4.0 International License, which permits use, sharing, adaptation, distribution and reproduction in any medium or format, as long as you give appropriate credit to the original author(s) and the source, provide a link to the Creative Commons license, and indicate if changes were made. The images or other third party material in this article are included in the article's Creative Commons license, unless indicated otherwise in a credit line to the material. If material is not included in the article's Creative Commons license and your intended use is not permitted by statutory regulation or exceeds the permitted use, you will need to obtain permission directly from the copyright holder. To view a copy of this license, visit http://creativecommons. org/licenses/by/4.0/.

\section{References}

1. Kerr JF, Wyllie AH, Currie AR. Apoptosis: a basic biological phenomenon with wide-ranging implications in tissue kinetics. $\mathrm{Br}$ J Cancer. 1972;26:239-57.

2. Malinen M, Niskanen EA, Kaikkonen MU, Palvimo JJ. Crosstalk between androgen and pro-inflammatory signaling remodels androgen receptor and NF-kappaB cistrome to reprogram the prostate cancer cell transcriptome. Nucleic Acids Res. 2017;45:619-30.

3. Zhang J, Gonit M, Salazar MD, Shatnawi A, Shemshedini L, Trumbly $\mathrm{R}$, et al. C/EBPalpha redirects androgen receptor signaling through a unique bimodal interaction. Oncogene. 2010;29:723-38.

4. Olokpa E, Moss PE, Stewart LV. Crosstalk between the androgen receptor and PPAR gamma signaling pathways in the prostate. PPAR Res. 2017;2017:9456020.

5. Sun J, Wang Y, Li Y, Zhao G. Downregulation of PPARgamma by miR-548d-5p suppresses the adipogenic differentiation of human bone marrow mesenchymal stem cells and enhances their osteogenic potential. J Transl Med. 2014;12:168.

6. Thorne JL, Maguire O, Doig CL, Battaglia S, Fehr L, Sucheston LE, et al. Epigenetic control of a VDR-governed feed-forward loop that regulatesp21(waf1/cip1) expression and function in nonmalignant prostate cells. Nucleic Acids Res. 2011;39:2045-56.

7. Long MD, Campbell MJ. Pan-cancer analyses of the nuclear receptor superfamily. Nucl Recept Res. 2015;2:pii: 101182.

8. Taylor BS, Schultz N, Hieronymus H, Gopalan A, Xiao Y, Carver $\mathrm{BS}$, et al. Integrative genomic profiling of human prostate cancer. Cancer Cell. 2010;18:11-22.

9. Cancer Genome Atlas Research Network The molecular taxonomy of primary prostate. Cancer Cell. 2015;163:1011-25.

10. Campbell MJ, Park S, Uskokovic MR, Dawson MI, Koeffler HP. Expression of retinoic acid receptor-beta sensitizes prostate cancer cells to growth inhibition mediated by combinations of retinoids and a 19-nor hexafluoride vitamin D3 analog. Endocrinology. 1998;139:1972-80.

11. Dou M, Zhou X, Fan Z, Ding X, Li L, Wang S, et al. Clinical significance of retinoic acid receptor beta promoter methylation in prostate cancer: a meta-analysis. Cell Physiol Biochem. 2018;45:2497-505.
12. Lohnes D, Kastner P, Dierich A, Mark M, LeMeur M, Chambon P. Function of retinoic acid receptor gamma in the mouse. Cell. 1993:73:643-58.

13. Lu XP, Fanjul A, Picard N, Shroot B, Pfahl M. A selective retinoid with high activity against an androgen-resistant prostate cancer cell type. Int J Cancer. 1999;80:272-8.

14. Hua S, Kittler R, White KP. Genomic antagonism between retinoic acid and estrogen signaling in breast cancer. Cell. 2009;137:1259-71.

15. Kittler R, Zhou J, Hua S, Ma L, Liu Y, Pendleton E, et al. A comprehensive nuclear receptor network for breast cancer cells. Cell Rep. 2013;3:538-51.

16. Dingwall M, Marchildon F, Gunanayagam A, Louis CS, WiperBergeron N. Retinoic acid-induced Smad3 expression is required for the induction of osteoblastogenesis of mesenchymal stem cells. Differentiation. 2011;82:57-65.

17. Rivera-Gonzalez GC, Droop AP, Rippon HJ, Tiemann K, Pellacani D, Georgopoulos LJ, et al. Retinoic acid and androgen receptors combine to achieve tissue specific control of human prostatic transglutaminase expression: a novel regulatory network with broader significance. Nucleic Acids Res. 2012;40:4825-40.

18. Dong D, Meng L, Yu Q, Tan G, Ding M, Tan Y. Stable expression of FoxA1 promotes pluripotent P19 embryonal carcinoma cells to be neural stem-like cells. Gene Expr. 2012;15:15362.

19. Ernst J, Kellis M. Chromatin-state discovery and genome annotation with ChromHMM. Nat Protoc. 2017;12:2478-92.

20. Andersson R, Gebhard C, Miguel-Escalada I, Hoof I, Bornholdt J, Boyd M, et al. An atlas of active enhancers across human cell types and tissues. Nature. 2014;507:455-61.

21. Urbanucci A, Sahu B, Seppala J, Larjo A, Latonen LM, Waltering $\mathrm{KK}$, et al. Overexpression of androgen receptor enhances the binding of the receptor to the chromatin in prostate cancer. Oncogene. 2012;31:2153-63.

22. Long MD, van den Berg PR, Russell JL, Singh PK, Battaglia S, Campbell MJ. Integrative genomic analysis in K562 chronic myelogenous leukemia cells reveals that proximal NCOR1 binding positively regulates genes that govern erythroid differentiation and Imatinib sensitivity. Nucleic Acids Res. 2015;43:7330-48.

23. Cai C, Chen S, Ng P, Bubley GJ, Nelson PS, Mostaghel EA, et al. Intratumoral de novo steroid synthesis activates androgen receptor in castration-resistant prostate cancer and is upregulated by treatment with CYP17A1 inhibitors. Cancer Res. 2011;71:650313.

24. Leushacke M, Barker N. Lgr5 and Lgr6 as markers to study adult stem cell roles in self-renewal and cancer. Oncogene. 2012;31:3009-22.

25. Dhiman VK, Attwood K, Campbell MJ, Smiraglia DJ. Hormone stimulation of androgen receptor mediates dynamic changes in DNA methylation patterns at regulatory elements. Oncotarget. 2015;6:42575-89.

26. Dweep H, Sticht C, Pandey P, Gretz N. miRWalk--database: prediction of possible miRNA binding sites by "walking" the genes of three genomes. J Biomed Inform. 2011;44:839-47.

27. Kwabi-Addo B, Giri D, Schmidt K, Podsypanina K, Parsons R, Greenberg N, et al. Haploinsufficiency of the Pten tumor suppressor gene promotes prostate cancer progression. Proc Natl Acad Sci USA. 2001;98:11563-8.

28. Foster BA, Gingrich JR, Kwon ED, Madias C, Greenberg NM. Characterization of prostatic epithelial cell lines derived from transgenic adenocarcinoma of the mouse prostate (TRAMP) model. Cancer Res. 1997;57:3325-30.

29. Ellis L, Ku S, Li Q, Azabdaftari G, Seliski J, Olson B, et al. Generation of a C57BL/6 MYC-driven mouse model and cell line of prostate cancer. Prostate. 2016;76:1192-202. 
30. Bao YH, Wang Y, Liu Y, Wang S, Wu B. MiR-96 expression in prostate cancer and its effect on the target gene regulation. Eur Rev Med Pharmacol Sci. 2017;21:4548-56.

31. Haflidadottir BS, Larne O, Martin M, Persson M, Edsjo A, Bjartell A, et al. Upregulation of miR-96 enhances cellular proliferation of prostate cancer cells through FOXO1. PLoS One. 2013;8:e72400.

32. Mihelich BL, Khramtsova EA, Arva N, Vaishnav A, Johnson DN, Giangreco AA, et al. miR-183-96-182 cluster is overexpressed in prostate tissue and regulates zinc homeostasis in prostate cells. $\mathbf{J}$ Biol Chem. 2011;286:44503-11.

33. Wang BD, Ceniccola K, Yang Q, Andrawis R, Patel V, Ji Y, et al. Identification and functional validation of reciprocal microRNAmRNA pairings in African American prostate cancer disparities. Clin Cancer Res. 2015;21:4970-84.

34. Tan SM, Lieberman J. Capture and identification of miRNA targets by biotin pulldown and RNA-seq. Methods Mol Biol. 2016;1358:211-28.

35. Guyot R, Vincent S, Bertin J, Samarut J, Ravel-Chapuis P. The transforming acidic coiled coil (TACC1) protein modulates the transcriptional activity of the nuclear receptors TR and RAR. BMC Mol Biol. 2010;11:3.

36. Luo Z, Gao X, Lin C, Smith ER, Marshall SA, Swanson SK, et al. $\mathrm{Zic} 2$ is an enhancer-binding factor required for embryonic stem cell specification. Mol Cell. 2015;57:685-94.

37. Qiu JJ, Lu X, Zeisig BB, Ma Z, Cai X, Chen S, et al. Leukemic transformation by the APL fusion protein PRKAR1A-RAR \{alpha\} critically depends on recruitment of RXR \{alpha\}. Blood. 2010;115:643-52.

38. Ozpolat B, Akar U, Zorrilla-Calancha I, Vivas-Mejia P, AcevedoAlvarez M, Lopez-Berestein G. Death-associated protein 5 (DAP5/p97/NAT1) contributes to retinoic acid-induced granulocytic differentiation and arsenic trioxide-induced apoptosis in acute promyelocytic leukemia. Apoptosis. 2008;13:915-28.

39. Johannesson M, Stahlberg A, Ameri J, Sand FW, Norrman K, Semb H. FGF4 and retinoic acid direct differentiation of hESCs into PDX1-expressing foregut endoderm in a time- and concentration-dependent manner. PLoS One. 2009;4:e4794.

40. Hindley CJ, Condurat AL, Menon V, Thomas R, Azmitia LM, Davis JA, et al. The Hippo pathway member YAP enhances human neural crest cell fate and migration. Sci Rep. 2016;6:23208.

41. Zhang K, Wang YW, Wang YY, Song Y, Zhu J, Si PC, et al. Identification of microRNA biomarkers in the blood of breast cancer patients based on microRNA profiling. Gene. 2017;619:10-20.

42. Liu P, Ramachandran S, Ali Seyed M, Scharer CD, Laycock N, Dalton WB, et al. Sex-determining region $\mathrm{Y}$ box 4 is a transforming oncogene in human prostate cancer cells. Cancer Res. 2006;66:4011-9.

43. Kinzler KW, Nilbert MC, Vogelstein B, Bryan TM, Levy DB, Smith KJ, et al. Identification of a gene located at chromosome $5 \mathrm{q} 21$ that is mutated in colorectal cancers. Science. 1991;251:1366-70.

44. Thu KL, Radulovich N, Becker-Santos DD, Pikor LA, Pusic A, Lockwood WW, et al. SOX15 is a candidate tumor suppressor in pancreatic cancer with a potential role in Wnt/beta-catenin signaling. Oncogene. 2014;33:279-88.

45. Roadmap Epigenomics C, Kundaje A, Meuleman W, Ernst J, Bilenky M, Yen A, et al. Integrative analysis of 111 reference human epigenomes. Nature. 2015;518:317-30.

46. Simandi Z, Horvath A, Wright LC, Cuaranta-Monroy I, De Luca I, Karolyi K, et al. OCT4 acts as an integrator of pluripotency and signal-induced differentiation. Mol Cell. 2016;63:647-61.

47. Chen CF, Goyette P, Lohnes D. RARgamma acts as a tumor suppressor in mouse keratinocytes. Oncogene. 2004;23:5350-9.
48. Kashyap V, Laursen KB, Brenet F, Viale AJ, Scandura JM, Gudas LJ. RARgamma is essential for retinoic acid induced chromatin remodeling and transcriptional activation in embryonic stem cells. J Cell Sci. 2013;126:999-1008.

49. Jin F, Liu X, Zhou Z, Yue P, Lotan R, Khuri FR, et al. Activation of nuclear factor-kappaB contributes to induction of death receptors and apoptosis by the synthetic retinoid CD437 in DU145 human prostate cancer cells. Cancer Res. 2005;65:6354-63.

50. McBurney MW, Costa S, Pratt MA. Retinoids and cancer: a basis for differentiation therapy. Cancer Invest. 1993;11:590-8.

51. Singal R, Ferdinand L, Reis IM, Schlesselman JJ. Methylation of multiple genes in prostate cancer and the relationship with clinicopathological features of disease. Oncol Rep. 2004;12:631-7.

52. McCormick DL, Rao KV, Steele VE, Lubet RA, Kelloff GJ, Bosland MC. Chemoprevention of rat prostate carcinogenesis by 9-cis-retinoic acid. Cancer Res. 1999;59:521-4.

53. Pili R, Salumbides B, Zhao M, Altiok S, Qian D, Zwiebel J, et al. Phase I study of the histone deacetylase inhibitor entinostat in combination with 13-cis retinoic acid in patients with solid tumours. Br J Cancer. 2012;106:77-84.

54. Ferrari AC, Stone N, Stock R, Bednar M, Esseesse I, Singh H, et al. 13-cis retinoic acid and complete androgen blockade in advanced hormone-naive prostate cancer patients: report of a phase II randomized study. J Clin Oncol. 2002;20:538-44.

55. Trump DL, Smith DC, Stiff D, Adedoyin A, Day R, Bahnson RR, et al. A phase II trial of all-trans-retinoic acid in hormonerefractory prostate cancer: a clinical trial with detailed pharmacokinetic analysis. Cancer Chemother Pharmacol. 1997;39:34956.

56. Beydoun HA, Shroff MR, Mohan R, Beydoun MA. Associations of serum vitamin $A$ and carotenoid levels with markers of prostate cancer detection among US men. Cancer Causes Control. 2011;22:1483-95.

57. Nash SH, Till C, Song X, Lucia MS, Parnes HL, Thompson IM, et al. Serum retinol and carotenoid concentrations and prostate cancer risk: results from the Prostate Cancer Prevention Trial. Cancer Epidemiol Biomark Prev. 2015;24:1507-15.

58. Trump DL. Retinoids in bladder, testis and prostate cancer: epidemiologic, pre-clinical and clinical observations. Leukemia. 1994;8(Suppl 3):S50-54.

59. Ngollo M, Lebert A, Dagdemir A, Judes G, Karsli-Ceppioglu S, Daures $\mathrm{M}$, et al. The association between histone 3 lysine 27 trimethylation (H3K27me3) and prostate cancer: relationship with clinicopathological parameters. BMC Cancer. 2014;14:994.

60. Weinstein JN, Collisson EA, Mills GB, Shaw KR, Ozenberger BA. et al.Cancer Genome Atlas Research Network The Cancer Genome Atlas Pan-Cancer analysis project. Nat Genet. 2013;45:1113-20.

61. Cancer Genome Atlas Research Network.Molecular taxonomy of primary prostate cancer. Cell. 2015;163:1011-25.

62. Fraser M, Sabelnykova VY, Yamaguchi TN, Heisler LE, Livingstone J, Huang V. et al. Genomic hallmarks of localized, non-indolent prostate cancer. Nature. 2017;541:359-64.

63. Sanda MG, Feng Z, Howard DH, Tomlins SA, Sokoll LJ, Chan DW. et al. Association between combined TMPRSS2:ERG and PCA3 RNA urinary testing and detection of aggressive prostate cancer. JAMA Oncol. 2017;3:1085-93.

64. Tomlins SA, Rhodes DR, Perner S, Dhanasekaran SM, Mehra R, Sun XW, et al. Recurrent fusion of TMPRSS2 and ETS transcription factor genes in prostate cancer. Science. 2005;310: 644-8.

65. Ulz P, Belic J, Graf R, Auer M, Lafer I, Fischereder K, et al. Whole-genome plasma sequencing reveals focal amplifications as a driving force in metastatic prostate cancer. Nat Commun. 2016;7:12008. 
66. Wang J, Cai Y, Shao LJ, Siddiqui J, Palanisamy N, Li R, et al. Activation of NF- $\{$ kappa $\}$ B by TMPRSS2/ERG fusion isoforms through Toll-like receptor-4. Cancer Res. 2011;71:1325-33.

67. Itkonen HM, Brown M, Urbanucci A, Tredwell G, Ho Lau C, Barfeld S, et al. Lipid degradation promotes prostate cancer cell survival. Oncotarget. 2017;8:38264-75.

68. McGrath MJ, Binge LC, Sriratana A, Wang H, Robinson PA, Pook D, et al. Regulation of the transcriptional coactivator FHL2 licenses activation of the androgen receptor in castrate-resistant prostate cancer. Cancer Res. 2013;73:5066-79.

69. Brohee L, Demine S, Willems J, Arnould T, Colige AC, Deroanne CF. Lipin-1 regulates cancer cell phenotype and is a potential target to potentiate rapamycin treatment. Oncotarget. 2015;6:11264-80.

70. Abe M, Xie W, Regan MM, King IB, Stampfer MJ, Kantoff PW, et al. Single-nucleotide polymorphisms within the antioxidant defence system and associations with aggressive prostate cancer. BJU Int. 2011;107:126-34.

71. Murillo-Garzon V, Kypta R. WNT signalling in prostate cancer. Nat Rev Urol. 2017;14:683-96.

72. Liu N, Mei L, Fan X, Tang C, Ji X, Hu X, et al. Phosphodiesterase 5/protein kinase $\mathrm{G}$ signal governs stemness of prostate cancer stem cells through Hippo pathway. Cancer Lett. 2016;378:38-50.

73. Zhang S, Yu M, Liu C, Wang L, Hu Y, Bai Y, et al. MIR-34c regulates mouse embryonic stem cells differentiation into male germ-like cells through RARg. Cell Biochem Funct. 2012;30:623-32.

74. Tsai YC, Chen WY, Siu MK, Tsai HY, Yin JJ, Huang J, et al. Epidermal growth factor receptor signaling promotes metastatic prostate cancer through microRNA-96-mediated downregulation of the tumor suppressor ETV6. Cancer Lett. 2017;384:1-8.

75. Mo W, Zhang J, Li X, Meng D, Gao Y, Yang S, et al. Identification of novel AR-targeted microRNAs mediating androgen signalling through critical pathways to regulate cell viability in prostate cancer. PLoS One. 2013;8:e56592.

76. Wilde JJ, Siegenthaler JA, Dent SY, Niswander LA. Diencephalic size is restricted by a novel interplay between GCN5 acetyltransferase activity and retinoic acid signaling. J Neurosci. 2017;37:2565-79.

77. Torrano V, Valcarcel-Jimenez L, Cortazar AR, Liu X, Urosevic J, Castillo-Martin M, et al. The metabolic co-regulator PGC1alpha suppresses prostate cancer metastasis. Nat Cell Biol. 2016;18:64556.

78. Alhasan AH, Scott AW, Wu JJ, Feng G, Meeks JJ, Thaxton CS, et al. Circulating microRNA signature for the diagnosis of very high-risk prostate cancer. Proc Natl Acad Sci USA. 2016;113:10655-60.

79. McDonald AC, Vira M, Shen J, Sanda M, Raman JD, Liao J, et al. Circulating microRNAs in plasma as potential biomarkers for the early detection of prostate cancer. Prostate. 2018;78:411-8.
80. Singh PK, Preus L, Hu Q, Yan L, Long MD, Morrison CD, et al. Serum microRNA expression patterns that predict early treatment failure in prostate cancer patients. Oncotarget. 2014;5:824-40.

81. Spahn M, Kneitz S, Scholz CJ, Stenger N, Rudiger T, Strobel P, et al. Expression of microRNA-221 is progressively reduced in aggressive prostate cancer and metastasis and predicts clinical recurrence. Int J Cancer. 2010;127:394-403.94

82. Jin M, Zhang T, Liu C, Badeaux MA, Liu B, Liu R, et al. miRNA128 suppresses prostate cancer by inhibiting BMI-1 to inhibit tumor-initiating cells. Cancer Res. 2014;74:4183-95.

83. Pi F, Binzel DW, Lee TJ, Li Z, Sun M, Rychahou P, et al. Nanoparticle orientation to control RNA loading and ligand display on extracellular vesicles for cancer regression. Nat Nanotechnol. 2018;13:82-89.

84. Campbell MJ, Carlberg C, Koeffler HP. A role for the PPARgamma in cancer therapy. PPAR Res. 2008;2008:314974.

85. Huang H, Xu Y, Zhu J, Li J. Recent advances in non-steroidal FXR antagonists development for therapeutic applications. Curr Top Med Chem. 2014;14:2175-87.

86. Viennois E, Mouzat K, Dufour J, Morel L, Lobaccaro JM, Baron S. Selective liver X receptor modulators (SLiMs): what use in human health? Mol Cell Endocrinol. 2012;351:129-41.

87. Gentleman RC, Carey VJ, Bates DM, Bolstad B, Dettling M, Dudoit S, et al. Bioconductor: open software development for computational biology and bioinformatics. Genome Biol. 2004;5: R80.

88. Ambrosone CB, Nesline MK, Davis W. Establishing a cancer center data bank and biorepository for multidisciplinary research. Cancer Epidemiol Biomark Prev. 2006;15:1575-7.

89. Lun AT, Smyth GK. csaw: a Bioconductor package for differential binding analysis of ChIP-seq data using sliding windows. Nucleic Acids Res. 2016;44:e45.

90. Zhu LJ, Gazin C, Lawson ND, Pages H, Lin SM, Lapointe DS, et al. ChIPpeakAnno: a Bioconductor package to annotate ChIPseq and ChIP-chip data. BMC Bioinforma. 2010;11:237.

91. Ritchie ME, Phipson B, Wu D, Hu Y, Law CW, Shi W, et al. limma powers differential expression analyses for RNAsequencing and microarray studies. Nucleic Acids Res. 2015;43: e47.

92. Love MI, Huber W, Anders S. Moderated estimation of fold change and dispersion for RNA-seq data with DESeq2. Genome Biol. 2014;15:550.

93. Bolton EC, So AY, Chaivorapol C, Haqq CM, Li H, Yamamoto KR. Cell- and gene-specific regulation of primary target genes by the androgen receptor. Genes Dev. 2007;21:2005-17.

94. Zhang D, Park D, Zhong Y, Lu Y, Rycaj K, Gong S, et al. Stem cell and neurogenic gene-expression profiles link prostate basal cells to aggressive prostate cancer. Nat Commun. 2016;7:10798. 